Old Dominion University

ODU Digital Commons

CCPO Publications

Center for Coastal Physical Oceanography

1994

\title{
Continuous Assimilation of Geosat Altimeter Data into a Three-Dimensional Primitive Equation Gulf Stream Model
}

Tal Ezer

Old Dominion University, tezer@odu.edu

George L. Mellor

Follow this and additional works at: https://digitalcommons.odu.edu/ccpo_pubs

Part of the Climate Commons, Meteorology Commons, and the Oceanography Commons

\section{Repository Citation}

Ezer, Tal and Mellor, George L., "Continuous Assimilation of Geosat Altimeter Data into a Three-Dimensional Primitive Equation Gulf Stream Model" (1994). CCPO Publications. 108.

https://digitalcommons.odu.edu/ccpo_pubs/108

\section{Original Publication Citation}

Ezer, T., \& Mellor, G.L. (1994). Continuous assimilation of geosat altimeter data into a three-dimensional primitive equation Gulf Stream model. Journal of Physical Oceanography, 24(4), 832-847. doi: 10.1175/1520-0485(1994)0242.0.CO;2

This Article is brought to you for free and open access by the Center for Coastal Physical Oceanography at ODU Digital Commons. It has been accepted for inclusion in CCPO Publications by an authorized administrator of ODU Digital Commons. For more information, please contact digitalcommons@odu.edu. 


\title{
Continuous Assimilation of Geosat Altimeter Data into a Three-Dimensional Primitive Equation Gulf Stream Model
}

\author{
TAL EZER AND GeORGE L. MELlor \\ Atmospheric and Oceanic Sciences Program, Princeton University, Princeton, New Jersey
}

(Manuscript received 4 September 1992, in final form 24 September 1993)

ABSTRACT

\begin{abstract}
A three-dimensional data assimilation scheme is described and tested, using the Geosat altimeter data and a high-resolution, primitive equation, numerical ocean model of the Gulf Stream region. The assimilation scheme is based on an optimal interpolation approach in which data along satellite tracks are continuously interpolated horizontally and vertically into the model grid and assimilated with the model prognostic fields. Preprocessed correlations between surface elevation anomalies and subsurface temperature and salinity anomalies are used to project surface information into the deep ocean; model and data error estimates are used to optimize the assimilation. Analysis fields derived from the Navy's Optimum Thermal Interpolation System are used to initialize the model and to provide some estimate of errors.

To evaluate the effectiveness of the assimilation scheme, the errors of model oceanic fields (surface elevation, Gulf Stream axis, temperature) with data assimilation are compared with errors without data assimilation (i.e., a pure forecast). Although some mesoscale meanders and rings are not well produced by the assimilation model, consistent reduction of errors by the assimilation is demonstrated. The vertical distribution of errors reveals that the scheme is most effective in nowcasting temperatures at middepth (around $500 \mathrm{~m}$ ) and less effective near the surface and in the deep ocean. The scheme is also more effective in nowcasting the Gulf Stream axis location than in nowcasting temperature variations. A comparison of the assimilation scheme during two periods shows that the nowcast skill of the assimilated model is reduced in May-September 1988, compared to MayJuly 1987 , due to poor coverage of the altimeter data during 1988.

This paper is one step toward a dynamic model and data assimilation system, which when fully developed,
\end{abstract} should provide useful nowcast and forecast information.

\section{Introduction}

Satellite-derived altimeter data, such as those obtained from Geosat, provide a global coverage of the World Ocean, and, together with a numerical model and a data assimilation scheme, can contribute to nowcasts of complete oceanic fields. However, unlike numerical weather prediction models, which operationally assimilate atmospheric observations (e.g., Parrish and Derber 1992), data assimilation in ocean models is in an early developmental stage although progress has been achieved during the last few years (e.g., Robinson et al. 1989; Holland and MalanotteRizzoli 1989; White et al. 1990; Mellor and Ezer 1991; Dombrowsky and De May 1992; Verron 1992).

One of the main obstacles in oceanic data assimilation is the overly sparse coverage of oceanic observations for either assimilation or evaluation. Oceanic fields that are measured globally, such as satellite-derived altimetry or sea surface temperature (SST) data, provide only surface information and even at the sur-

Corresponding author address: Dr. Tal Ezer, Atmospheric and Oceanic Sciences, Princeton University, Sayre Hall, P.O. Box CN710, Princeton, NJ 08544-0710. face they are incomplete; that is, altimetry is measured only along satellite tracks and SST data are missing in areas with cloud coverage. Therefore, a realistic nowcast system will require a sophisticated data assimilation scheme to fill in missing information in space and time.

Some of the altimetric data assimilation techniques that have been developed include, for example, predetermined "feature models" (Robinson et al. 1989), Kalman filter (Miller 1989), updating potential vorticity (Haines 1991), the adjoint method (Moore 1991), "nudging" (Verron 1992), and optimal interpolation (White et al. 1990; Dombrowsky and De May 1992). At the present time, there is no consensus as to the best way of assimilating altimeter data into an ocean model; different techniques are still being studied and tested [see also Ghil and Malanotte-Rizzoli (1991) for a review of different schemes]. Because of the complexity of the problem and because of computational resource limitations, all of the above techniques were tested with relatively simple models (e.g., quasigeostrophic dynamics and simple domain and bottom topography). Only a few altimetric data assimilation schemes have been developed for primitive equation models with realistic topography. An exception is the study of Mellor and Ezer (1991), who used an optimal 
interpolation (OI) technique, together with preprocessed correlations between surface elevation and subsurface temperature and salinity fields to assimilate Geosat-type data into their primitive equation Gulf Stream model. While the latter study used simulated data in the "identical twin" sense, here we test the scheme with real data for the first time. Some significant modifications of the OI scheme are introduced to accommodate data errors and model error growth.

When data assimilation techniques are tested using observed altimeter data, evaluation of the method is difficult because other independent observations of the three-dimensional oceanic fields, which are provided perfectly by the "true" ocean in identical twin experiments, are not readily available. Here, we use analysis fields derived from the U.S. Navy's Optimum Thermal Interpolation System (Clancy et al. 1990, 1992; Cummings and Ignaszewski 1991) to initialize the model and then to compare with model fields for separate runs with assimilation of altimeter data and without assimilation. A more detailed description of the OTIS system is given later.

Experiments by Ezer et al. (1992), using the OTIS data to initialize the same model presented here, showed some forecast skill, better than persistence (a forecast based on no change), for at least two weeks. The evaluation of the assimilation technique is especially difficult because of the differences in the variability of the OTIS fields and the Geosat altimeter data, as indicated by Ezer et al. (1993). However, it provides a first comparison of nowcast fields from a realistic assimilated model with three-dimensional temperature and salinity synoptic "observations."

The main goal here is to test the feasibility of operational dynamic assimilation of altimeter data into a realistic numerical ocean model. We will evaluate whether the assimilation of altimeter data can improve the model forecast and how the amount of data available for assimilation affects the forecast skill. Ultimately, it is expected that the surface SST signature, upon which OTIS fields are heavily reliant, will be combined with altimetry for direct insertion into our dynamic model. Other data sources will be added in the course of system development.

The data and the numerical model are described in section 2. The data assimilation scheme is described in section 3 and then tested in section 4, using Geosat altimeter data. Finally, section 5 provides discussion and conclusions of the study.

\section{Description of the data and the numerical model}

\section{a. The OTIS temperature and salinity data}

Synoptic analysis fields of temperature and salinity are obtained from the Optimum Thermal Interpolation System (OTIS). The global-scale system is described in detail by Clancy et al. $(1990,1992)$. Here, we use the regional-scale high-resolution version of OTIS de- scribed by Cummings and Ignaszewski (1991), implemented for the Navy project, Data Assimilation and Model Evaluation Experiments (Leese et al. 1992). Satellite infrared images are used to identify the Gulf Stream north wall and rings (by S. Glenn, personal communication). Then, feature models, describing the shape of the stream and rings, project the surface information into the deep layers, producing three-dimensional synthetic temperature and salinity fields. The synthetic fields plus the Multi-Channel Sea Surface Temperature (MCSST) data used directly at the surface, climatology from the Navy's General Digital Environmental Model (GDEM), and expendable bathythermograph (XBT) data are used to produce the threedimensional thermal field via an optimal interpolation method. As will be shown later, the resultant OTIS fields are dominated by the feature model. The data are projected on a $0.2^{\circ} \times 0.2^{\circ}$ horizontal grid and 34 vertical levels.

\section{b. The Geosat altimeter data}

The altimeter data used here are from the Exact Repeat Mission (ERM) of the Geodetic Earth Orbiting Satellite (Geosat) covering a two-year period from November 1986 to November 1988 . The data are available approximately every $7 \mathrm{~km}$ along each track, which repeats approximately every 17 days. In the modeled area there are typically two tracks per day. Quality control and editing were applied to this dataset, and long wavelength periodic orbit errors were removed from the data (Sirkes and Wunsch 1990). For the Gulf Stream region, all tracks within $20^{\circ}-50^{\circ} \mathrm{N}, 40^{\circ}-80^{\circ} \mathrm{W}$ and where water depth is greater than $1000 \mathrm{~m}$ were used. In this area, the mean elevation along each track is obtained from all available repeat cycles and removed from the individual repeat cycles. Here we refer to these data as Geosat anomaly data or, simply, Geosat data. Usually, to construct synoptic surface elevation fields from the altimeter anomaly observations, a so-called "synthetic geoid" (the elevation mean field relative to the geoid) is needed; different techniques used to estimate this mean elevation field can be found, for example, in Glenn et al. (1991), Kelly (1991), and Ezer et al. (1993). However, in the dynamic assimilation described here, it is assumed that the model mean elevation field and the (unknown) ocean mean field are the same. This can be a source of error, among others discussed at the end of this paper.

\section{c. The numerical ocean model}

The model used here is the Princeton primitive equation ocean model described by Blumberg and Mellor (1987) and Mellor (1992); it includes the turbulence submodel of Mellor and Yamada (1982) to provide vertical mixing parameters. The model has been used for many applications such as estuaries and 
bays (Oey et al. 1985a,b; Galperin and Mellor $1990 \mathrm{a}, \mathrm{b}$ ), semienclosed seas (the Gulf of Mexico and the Mediterranean Sea), and for coastal regions around the world. In the Gulf Stream region, the model has been used before (in a version with a smaller domain and coarser resolution) for data assimilation studies (Mellor and Ezer 1991; Ezer et al. 1991), for Gulf Stream separation and surface forcing sensitivity studies (Ezer and Mellor 1992), and for studying the interaction of the Gulf Stream with the coastal ocean (Oey et al. 1992). The version of the Gulf Stream model used here, has an extended domain and higher resolution than the previous model; it has been used in studies of mesoscale variabilities in altimetry and SST data (Ezer et al. 1993), in forecast experiments (Ezer et al. 1992), and in studies of the interaction between the Gulf Stream and the New England Seamounts Chain (Ezer 1994).

The prognostic variables of the model are temperature, $T$; salinity, $S$; the free surface elevation, $\eta$; velocities, $u, v, w$; and the turbulent kinetic energy. The model has a bottom-following sigma coordinate vertical system, with 15 levels in this application, and a curvilinear orthogonal, coastal-following horizontal grid with a typical resolution of $10-18 \mathrm{~km}$ in the Gulf Stream region; see Fig. 1 for the grid and the bottom topography. The data assimilation experiments were performed in the smaller subdomain, indicated in Fig. la to reduce computer memory, because of the poor quality of the OTIS data far from the Gulf Stream and upstream of Cape Hatteras and because this subdomain represents the most active region of the Gulf Stream.

The larger model was initialized with temperature and salinity data obtained from OTIS; then it was run for 10 days in a diagnostic mode (holding the temperature and the salinity fixed ) to obtain the dynamically adjusted velocities and surface elevations. Previous studies (Ezer and Mellor 1992; Ezer et al. 1992, 1993) indicate a very rapid diagnostic adjustment of velocity and elevation to the initial density field. The total streamfunction on the boundaries is set according to basin-scale diagnostic calculations (Mellor et al. 1982) and observations. An inflow of $30 \mathrm{~Sv}\left(1 \mathrm{~Sv} \equiv 10^{6}\right.$ $\mathrm{m}^{3} \mathrm{~s}^{-1}$ ) is prescribed at the Florida Straits (the southwestern corner of the domain), a slope water inflow of $30 \mathrm{~Sv}$ enters at the north part of the eastern boundary, an inflow of $40 \mathrm{~Sv}$ from the subtropical gyre enters at the southeast and the south boundaries, and 100-Sv Gulf Stream outflow is allowed to exit the domain on the eastern boundary between $38^{\circ}$ and $39^{\circ} \mathrm{N}$. Together with temperature and salinity, the velocities from this diagnostic calculation are used to initialize the smaller subdomain model and to set the vertically averaged inflow/outflow velocities on its boundaries. Internal velocities on the open boundaries are governed by the Sommerfeld radiation conditions [ see Mellor and Ezer (1991) and Ezer and Mellor (1992) for more details on the boundary conditions of the Gulf stream model].
The surface forcing includes heat flux and wind stress fields obtained from the monthly climatologies of the Comprehensive Ocean-Atmosphere Data Set (COADS) analyzed by Oberhuber (1988); the formulation of the surface forcing in the model is described in detail by Ezer and Mellor (1992), who show the importance of the surface forcing in obtaining a realistic separation of the Gulf Stream at Cape Hatteras.

\section{The data assimilation scheme}

\section{a. The assimilation approach}

The goal here is to continuously assimilate altimetry anomaly data (the mean ocean signal is removed), subsampled along satellite tracks (an average of two tracks per day), into three-dimensional model fields of temperature, $T$, or salinity, $S$. The three-dimensional problem is divided into two steps. First, we solve a twodimensional problem by assimilating surface elevation, $\eta$, from the data along satellite tracks and interpolating the data into the model grid. Then, we solve a onedimensional problem, in the vertical, by using the analysis elevation fields (already interpolated into the model grid) and correlation factors that relate surface elevation anomalies and subsurface $T$ and $S$ anomalies. The data and the model first guess error estimates are taken into account in the first step of the OI, while errors in the surface to subsurface correlations are taken into account in the second step. A simplified schematic diagram of the data assimilation approach is shown in Fig. 2. In the following, we describe the assimilation scheme for temperature fields; a similar approach is applied to salinity fields.

The basis of our scheme for the projection of surface information into subsurface fields is the relation

$$
\delta T(x, y, z, t)=F^{T}(x, y, z) \delta \eta(x, y, t),
$$

where $F^{T}$ is a predetermined function independent of time. The anomalies, $\delta T(x, y, z, t)$ and $\delta \eta(x, y, t)$, are the instantaneous temperatures and elevations minus their time-averaged values. In this paper, the horizontal coordinates $(x, y)$ are equivalent to (longitude, latitude). In the following, each model grid point, $i$, represents either the location $\left(x_{i}, y_{i}, z_{i}\right)$ for three-dimensional fields (e.g., $T)$ or $\left(x_{i}, y_{i}\right)$ for two-dimensional fields (e.g., $\eta$ ). The correlation factors, $F_{i}^{T}$, and the correlation coefficients, $C_{i}^{T}$, between surface elevation anomalies $\delta \eta_{i}(t)$ and subsurface temperature anomalies $\delta T_{i}(t)$ are calculated at each model grid point and defined by

$$
F_{i}^{T}=\frac{\overline{\left(\delta T_{i} \delta \eta_{i}\right)}}{\overline{\delta \eta_{i}^{2}}}, \quad C_{i}^{T}=\frac{\overline{\left(\delta T_{i} \delta \eta_{i}\right)}}{\left[\overline{\delta T_{i}^{2} \delta \eta_{i}^{2}}\right]^{1 / 2}},
$$

where an overbar represents a time average. The spatial distribution of the correlation coefficients derived from one year of model simulations is shown in Mellor and Ezer (1991); in the vicinity of the Gulf Stream (about 
(A) MODEL GRID

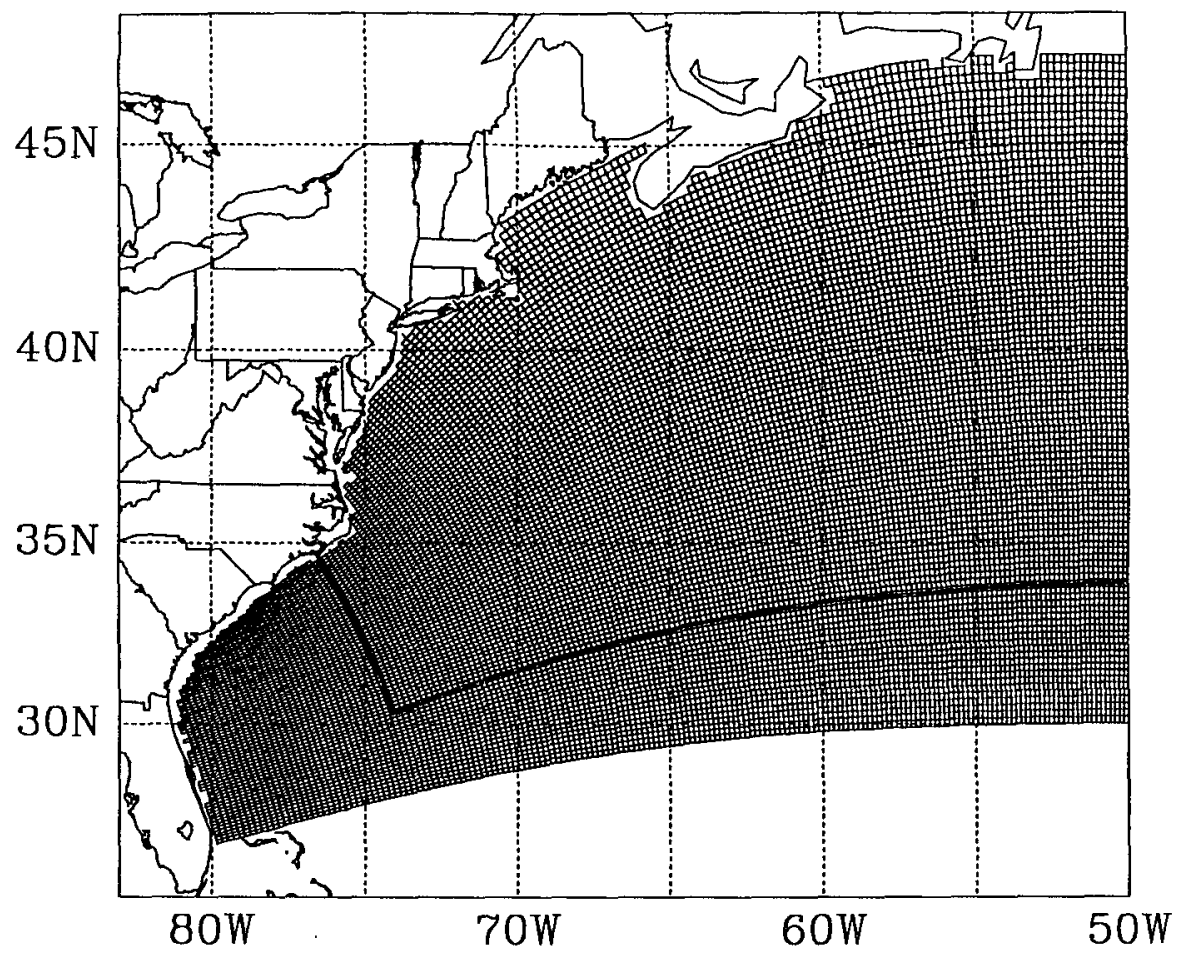

(B) BOTTOM TOPOGRAPHY

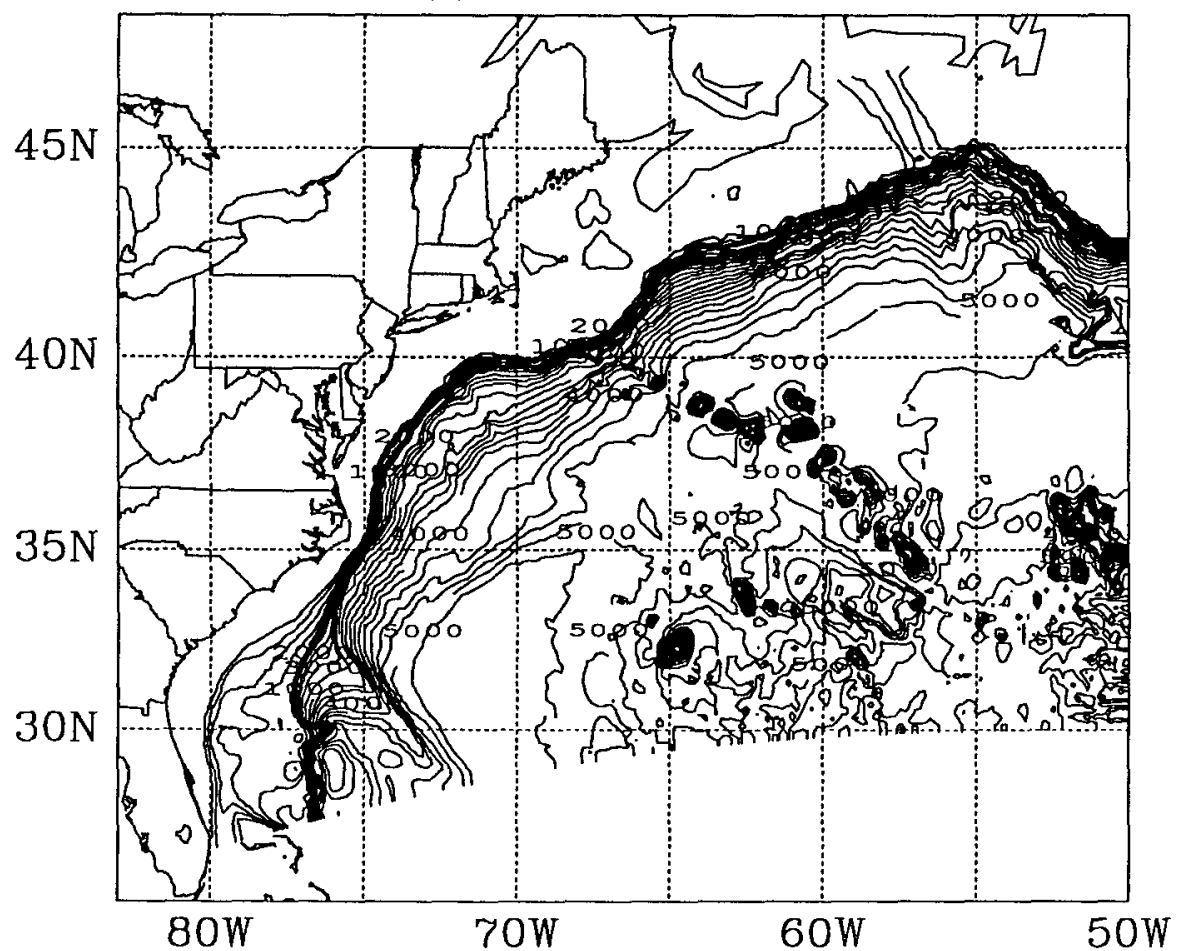

FlG. 1. (a) The curvilinear orthogonal model grid. The inner boundaries represent the subdomain in which data assimilation is done; diagnostic calculations in the large domain provides boundary conditions for the subdomain model. (b) The bottom topography of the model; the contour interval is $200 \mathrm{~m}$. The actual coastal boundary of the model domain is at the $10-\mathrm{m}$ depth isobath. 
AREA AVR. TEMPERATURE

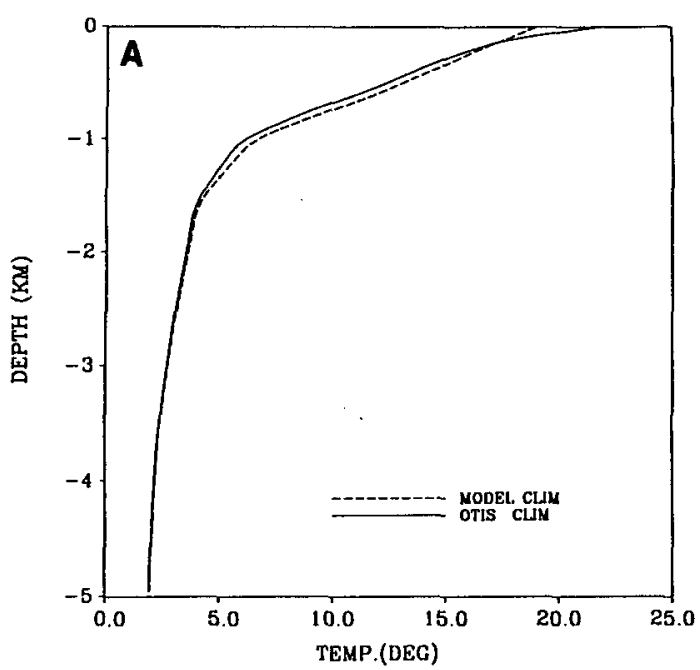

AREA AVR. CORR. FACT.

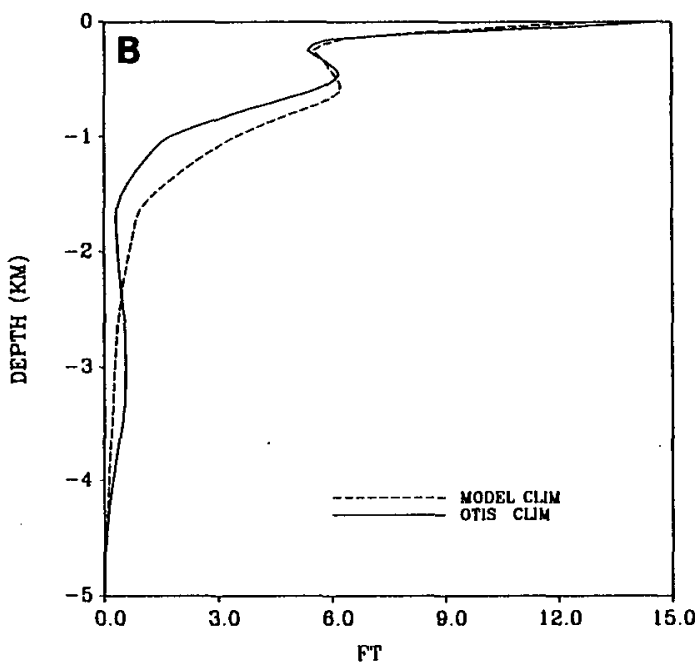

AREA AVR. CORR. COEF.

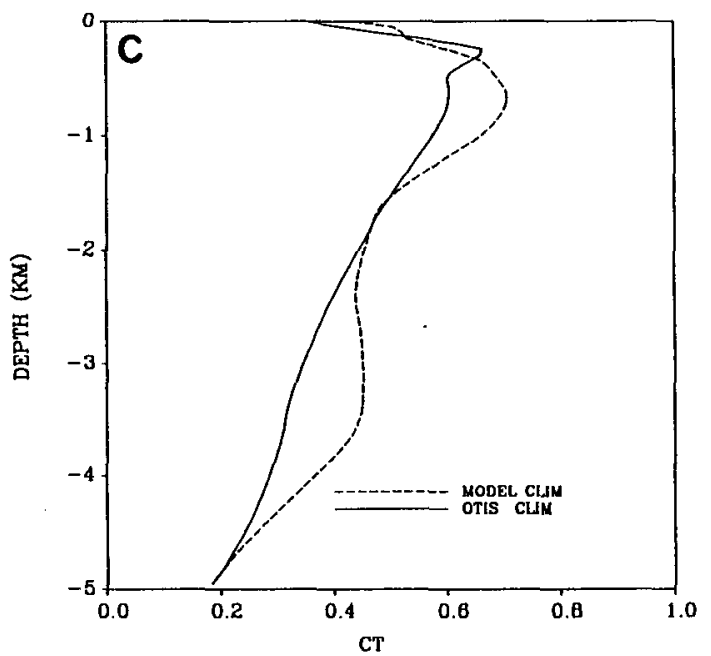

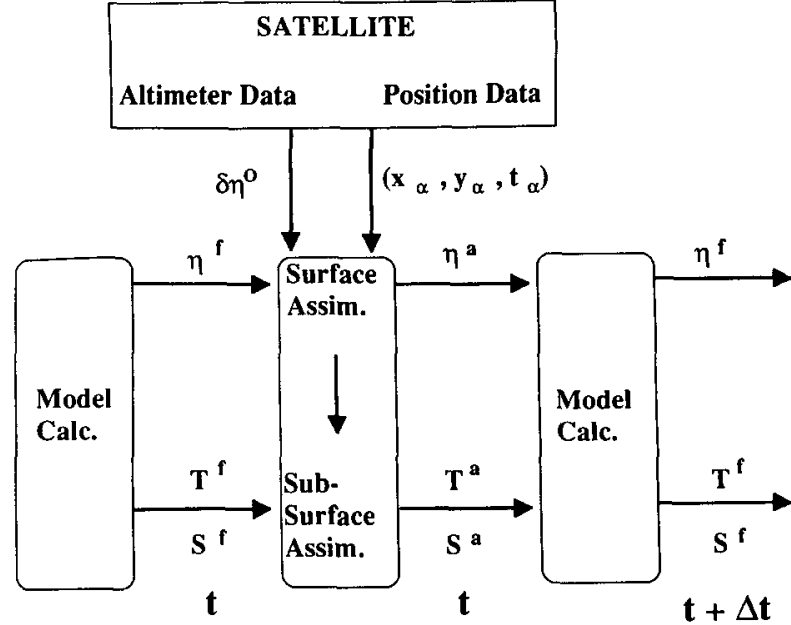

FIG. 2. A schematic diagram of the data assimilation scheme; the superscripts " $o$," "f," and "a" represent observations (i.e., from altimeter data), first guess (i.e., from model calculations), and analysis (i.e., from assimilation scheme) fields.

$2^{\circ}$ north and south of the mean location of the stream), $C^{T}$ values exceed 0.8 in the upper $1000 \mathrm{~m}$. Figure 3 shows the area-averaged profiles of $\bar{T}, F^{T}$, and $C^{T}$ calculated from the model output fields and from the OTIS analysis fields; each has $\mathrm{O}(30)$ samples. Although there are spatial differences (not shown) between the model and the OTIS climatologies, the area-averaged profiles are in relatively good agreement. We hope to use larger samples in the future in order to improve the statistics. Note that the best surface-subsurface correlation is found at about $500 \mathrm{~m}$ depth (Fig. 3c); we will see later how the vertical distribution of the nowcast error is affected by this distribution of the correlation coefficients. Figure 3 shows relatively small differences between the model and the data-derived correlations; we chose here to use the latter; assimilation experiments (not shown) where model instead of data statistics are used are slightly worse than those that are presented here.

Relations similar to (1) and (2a,b) are obtained for salinity and the corresponding correlation factors and coefficients, $F^{S}$ and $C^{S}$. However, since in this region the temperature has a larger influence on density than does the salinity, $C^{T}$ is generally larger than $C^{S}$, and the correlation coefficient for density is thus quite similar to $C^{T}$.

Suppose that, at a time $t$, altimeter data of all satellite tracks that passed the domain during a period, $\Delta t$, are

Fig. 3. Area-averaged profiles of (a) mean temperature (in ${ }^{\circ} \mathrm{C}$ ), (b) the correlation factor, $F^{T}$ (in ${ }^{\circ} \mathrm{C} \mathrm{m}^{-1}$ ), and (c) the correlation coefficients, $C^{T}$, between surface elevation anomaly and subsurface temperature anomaly. They are calculated from the model statistics (dashed lines) and from the OTIS analysis data (solid lines). 
to be assimilated into the model grid. The analysis elevation at a model grid point $\left(x_{i}, y_{i}\right)$ is given by

$$
\eta_{i}^{a}=\eta_{i}^{f}+\sum_{\alpha=1}^{N} P_{i \alpha}^{\eta}\left(\delta \eta_{\alpha}^{o}-\delta \eta_{\alpha}^{f}\right)
$$

to update each model grid point at the specified analysis time. The superscripts, $o$ and $f$, represent observation (i.e., altimetry anomaly data) and model first guess values, respectively. Greek subscripts represent data locations in space and time; $P_{l \alpha}^{\eta}$ are weighting factors to be defined below. The interpolation uses a maximum of $N$ data points. Next, the analysis temperature and salinity at each model grid point, $\left(x_{i}, y_{i}, z_{i}\right)$, are obtained by

$$
\begin{aligned}
T_{i}^{a}=T_{i}^{f}+P_{i}^{T} F_{i}^{T}\left(\eta_{i}^{a}-\eta_{i}^{f}\right), \\
S_{i}^{a}=S_{i}^{f}+P_{i}^{S} F_{i}^{S}\left(\eta_{i}^{a}-\eta_{i}^{f}\right) .
\end{aligned}
$$

The goal of the OI, described in the following section, is to calculate the weights $P^{\eta}(x, y), P^{T}(x, y, z)$, and $P^{S}(x, y, z)$; it is done by minimizing the analysis errors in (3) and (4), taking into account estimated model and data errors.

Note that, here and in Mellor and Ezer (1991), we use correlation factors between elevation and subsurface fields to extend surface information into the deep layers. An alternative technique (Carnes et al. 1990) uses correlations between dynamic height and the coefficients of empirical orthogonal functions (EOF) of observed vertical temperature profiles. We have also used this technique in the present context using the first three EOF modes (which account for about $95 \%$ of the temperature variance in this region; Cummings and Ignaszewski 1991) and found that it yields results virtually identical to our direct correlation technique.

\section{$b$. Calculating the weights for the surface elevation}

To calculate the weights in (3), we use an OI technique that is conventional to the meteorological community (Gustafson 1981). Predetermined and fixed error covariance matrices are invoked. This is in contrast to more recently developed or applied methods, which make use of the Kalman filter, an adjoint model, or other variational methods (e.g., Ghil and MalanotteRizzoli 1991; Parrish and Derber 1992; Zou et al. 1992). These methods are attractive because they produce more information and presumably reduce nowcast error. They are also computer intensive, whereas the OI scheme we use here increases the computations by only $10 \%-20 \%$ compared to the model itself without assimilation.

It seems necessary to initially repeat standard analysis so that terms are properly defined and so that ensuing nonstandard analysis may be understood. The first guess and the observed elevation anomaly fields are equated to their true anomaly, $\delta \eta$, plus errors, $\delta \eta^{\prime}$ and $\Delta \eta$ :

$$
\delta \eta^{f}=\delta \eta+\delta \eta^{\prime}, \quad \delta \eta^{o}=\delta \eta+\Delta \eta . \quad(5 \mathrm{a}, \mathrm{b})
$$

The mean square analysis error is $E_{i}^{a}=\overline{\left(\eta_{i}^{a}-\eta_{i}\right)^{2}}$, which, using ( 3 ) and (5a,b), becomes

$$
\begin{aligned}
E_{i}^{a}=\overline{\delta \eta_{i}^{\prime 2}} & -2 \sum_{\alpha=1}^{N} P_{i \alpha}^{\eta} \overline{\delta \eta_{\alpha}^{\prime 2}} \\
& +\sum_{\beta=1}^{N} \sum_{\alpha=1}^{N} P_{i \beta}^{\eta} P_{i \alpha}^{\eta}\left(\overline{\delta \eta_{\alpha}^{\prime} \delta \eta_{\beta}^{\prime}}+\overline{\Delta \eta_{\alpha} \Delta \eta_{\beta}}\right) .
\end{aligned}
$$

We now minimize the error with respect to the weighting parameters so that $\partial E_{i}^{a} / \partial P_{i \alpha}=0$ and obtain

$$
\begin{aligned}
\sum_{\alpha=1}^{N} P_{i \alpha}^{\eta}\left(\overline{\delta \eta_{\alpha}^{\prime} \delta \eta_{\beta}^{\prime}}+\overline{ }\right. & \left.\overline{\Delta \eta_{\alpha} \Delta \eta_{\beta}}\right) \\
& =\overline{\delta \eta_{i}^{\prime} \delta \eta_{\beta}^{\prime}}, \quad \beta=1, \cdots, N,
\end{aligned}
$$

where $\overline{\delta \eta_{\alpha}^{\prime} \delta \eta_{\beta}^{\prime}}$ and $\overline{\Delta \eta_{\alpha} \Delta \eta_{\beta}}$ are the first guess and observational error covariance matrices. We now model these matrices in a conventional manner so that

$$
\overline{\delta \eta_{\alpha}^{\prime} \delta \eta_{\beta}^{\prime}}=R_{\alpha} \overline{\delta \eta_{\alpha}^{2}} G_{\alpha \beta}, \quad \overline{\Delta \eta_{\alpha} \Delta \eta_{\beta}}=D_{\alpha} \overline{\delta \eta_{\alpha}^{2}} \delta_{\alpha \beta},
$$

where $R_{\alpha}$ is the first guess error covariance normalized by the model natural variability, $\overline{\delta \eta^{2}}$, and $D_{\alpha}$ is the normalized, data error covariance (noise to signal ratio); $\delta_{\alpha \beta}$ is the Kronecker delta function and

$$
\begin{array}{r}
G_{\alpha \beta} \equiv \exp \left[-k_{x}^{2}\left(x_{\alpha}-x_{\beta}\right)^{2}\right. \\
\left.-k_{y}^{2}\left(y_{\alpha}-y_{\beta}\right)^{2}-k_{t}^{2}\left(t_{\alpha}-t_{\beta}\right)^{2}\right]
\end{array}
$$

is the autocorrelation coefficient. The length and time scales, $k_{x}^{-1}, k_{y}^{-1}, k_{t}^{-1}$, are estimated directly from model statistics. The $N$ data points included in the analysis for each model grid point are those having the smallest values of $G_{\alpha \beta}$.

If $(8 a, b)$ and (9) are used in (7), we obtain

$$
\sum_{\alpha=1}^{N} P_{i \alpha}^{\eta}\left(R_{\alpha} G_{\alpha \beta}+D_{\alpha} \delta_{\alpha \beta}\right)=R_{i} G_{i \beta}, \quad \beta=1, \cdots, N
$$

Equation (10) is the primary OI matrix equation, which must be inverted to obtain $P_{l \alpha}^{\eta}$. We can also obtain a simplified analysis error by inserting (10) into (6) so that

$$
\frac{E_{i}^{a}}{\overline{\delta \eta^{2}}}=R_{i}\left[1-\sum_{\alpha=1}^{N} P_{i \alpha} G_{i \alpha}\right] .
$$

We now interpret the normalized first guess error, $R_{i}$, as that associated with the model output at time, $t$, and its value given by (11) as the reduced error after analysis. Next we define a cycle as the assimilation process plus a model run for the time interval, $\Delta t$, so that at the end of the cycle

$$
R_{i}^{t+\Delta t}=R_{i}^{t}\left[1-\sum_{\alpha=1}^{N} P_{i \alpha}^{\eta} G_{i \alpha}\right]+\left(R_{i}^{\infty}-R_{i}^{t}\right) \frac{\Delta t}{T_{C}},
$$


where we have added the second term on the right to account for model error growth rate. This linear-saturation, error growth model is consistent with our previous experience (Mellor and Ezer 1991) and with weather prediction results (Leith 1987). It can be shown that $R_{i}<R_{i}^{\infty}$ and that the maximum value of $R_{i}^{\infty}$ is 2 . Here $R_{i}$ approaches $R_{i}^{\infty}$ if no assimilation is applied for a period long compared with $T_{C} ; T_{C}=20$ days is approximated from the model error growth rates (Mellor and Ezer 1991). If the model has some intrinsic determinism, as it does for a wind-driven and tidally driven coastal and estuarine regions (Oey et al. 1985a,b; Galperin and Mellor 1990a,b), then $R_{i}^{\infty}<2$. However, for this study wherein the flow is dominated by the indeterministic Gulf Stream, we set $R_{i}^{\infty}=2$. In the future, the spatial distribution of $R_{i}^{\infty}$ can be estimated by an ensemble of model runs driven by synoptic winds but with different initial conditions.

c. Calculating the weights for the subsurface fields

If (3) is substituted into (4a), we obtain that

$$
T_{i}^{a}=T_{i}^{f}+P_{i}^{T} F_{i}^{T} \sum_{\alpha=1}^{N} P_{i}^{\eta}\left(\delta \eta_{\alpha}^{o}-\delta \eta_{\alpha}^{f}\right)
$$

Next, we form the analysis error

$$
\begin{aligned}
E_{i} \equiv & \overline{\left(T_{i}^{a}-T_{i}\right)^{2}} \\
= & \overline{\left\{T_{i}^{\prime}+P_{i}^{T}\left[F_{i}^{T} \sum_{\alpha} P_{i \alpha}^{\eta}\left(\Delta \eta_{\alpha}-\delta \eta_{\alpha}^{\prime}\right)+\Delta T_{i}\right]\right\}^{2}} \\
= & \overline{T_{i}^{\prime 2}}-2 P_{i}^{T} F_{i}^{T} \sum_{\alpha} P_{i \alpha}^{\eta} \overline{T_{i}^{\prime} \delta \eta_{\alpha}^{\prime}} \\
& +P_{i}^{r^{2}}\left\{F_{i}^{r^{2}} \sum_{\alpha} P_{i \alpha}^{\eta} \sum_{\beta} P_{i \beta}^{\eta}\right. \\
& \left.\times\left(\overline{\delta \eta_{\alpha}^{\prime} \delta \eta_{\beta}^{\prime}}+\overline{\Delta \eta_{\alpha} \Delta \eta_{\beta}}\right)+\overline{\Delta T_{i}^{2}}\right\},
\end{aligned}
$$

where the first guess model fields are taken as the real fields plus errors, $T^{f}=T+T^{\prime}$, and where we add $\Delta T_{i}$ to the right side of (13) before insertion into (14); $\Delta T_{i}$ is the error in the analysis temperature due to the imperfect correlation between surface elevation and subsurface temperature. In the derivation of (14), data errors and model errors are assumed to be uncorrelated.

Now, to find the weights, we minimize the analysis error in (14), $\partial E_{i} / \partial P_{i}^{T}=0$, and we obtain

$$
P_{i}^{T}=\frac{F_{i}^{T} \sum_{\alpha} P_{i \alpha}^{\eta} \overline{T_{i}^{\prime} \delta \eta_{\alpha}^{\prime}}}{F_{i}^{T^{2}} \sum_{\alpha} \sum_{\beta} P_{i a}^{\eta} P_{i \beta}^{\eta}\left(\overline{\delta \eta_{\alpha}^{\prime} \delta \eta_{\beta}^{\prime}}+\overline{\Delta \eta_{\alpha} \Delta \eta_{\beta}}\right)+\Delta T_{i}^{2}} .
$$

Using ( 1), we can write

$$
\overline{T_{i}^{\prime} \delta \eta_{\alpha}^{\prime}}=F_{i}^{T} \overline{\delta \eta_{i}^{\prime} \delta \eta_{\alpha}^{\prime}}
$$

and

$$
\overline{\Delta T_{i}^{2}}=F_{i}^{T^{2}} \overline{\delta \eta_{i}^{2}} \frac{\left(1-C_{i}^{T^{2}}\right)}{C_{i}^{T^{2}}}
$$

where the derivation of the correlation error, $(16 \mathrm{~b})$, is from Mellor and Ezer (1991). Equation (15) can be greatly simplified using (7) and previously defined normalizations so that

$$
P_{i}^{T}=\frac{R_{i} C_{i}^{T^{2}} \sum_{\alpha} P_{i \alpha}^{\eta} G_{i \alpha}}{R_{i} C_{i}^{T^{2}} \sum_{\alpha} P_{i \alpha}^{\eta} G_{i \alpha}+1-C_{i}^{T^{2}}} .
$$

Therefore, the weights for subsurface temperature (and similarly for salinity), increase with increasing first guess error and increasing surface to subsurface correlations. If the correlation is perfect, $C^{T}=1$, then $P^{T}$ is unity; on the other hand, if $C^{T}=0$, then $P^{T}=0$ (i.e., no updating of subsurface fields).

This data assimilation scheme is generally similar to the OI method of Mellor and Ezer (1991) with several improvements. Changes over the previous study include an improved error growth model, the inclusion of data errors, and the use of first guess model temperature and salinity fields in $(4 a, b)$ instead of the model climatology. The latter reduces the bias toward model climatology in the case where data and model mean fields are much different from each other.

Previous sensitivity studies evaluated the effects of the parameters of the OI scheme such as the length and time scales, the number of data points used to update each model grid point and the assimilation time step, $\Delta t$, on the resultant analysis fields (Mellor and Ezer 1991; Ezer et al. 1993). Based on these findings and the model statistics, the following parameters are chosen here: $k_{x}^{-1}=k_{y}^{-1}=170 \mathrm{~km}, k_{t}^{-1}=22$ days, $\Delta t$ $=1$ day, $N=8$.

The data error variance, $\overline{\Delta \eta^{2}}$, is about $25 \mathrm{~cm}^{2}$ for the Geosat altimeter data compared with a typical model elevation variance, $\delta \eta^{2}$, of about $1000 \mathrm{~cm}^{2}$ in the vicinity of the Gulf Stream, and reducing to about $25 \mathrm{~cm}^{2}$ sufficiently far from the stream; thus, $D$ varies between 0.025 and 1 . Therefore, more weight is given to the data in regions where the natural variability is larger (e.g., near the Gulf Stream front) compared to areas of relatively small variability (e.g., on the continental shelf). Unlike Mellor and Ezer (1991), who used a geostrophic adjustment technique to help the model adjust its velocity fields after each assimilation cycle, we did not find it necessary to do so here. With the inclusion of data errors in the scheme, the corrections to the first guess fields are relatively small, and the model velocity fields seem to adjust to changes in the density field in a short time (1-2 days) compared to the Geosat repeat cycle ( 17 days).

\section{Evaluation of the data assimilation scheme \\ a. The experiments}

The skill of the assimilation scheme is evaluated for two cases in which OTIS analysis fields were available: case 1, 6 May-21 July 1987; case 2, 4 May-21 Sep- 
tember 1988. In case 1, three OTIS fields were available at 7-day intervals at the beginning and three fields at the end of the period. In case 2 , the available OTIS fields were at 7-day intervals for the first three dates, and at 14-day intervals for the remaining period. The temperature and the salinity fields from the first OTIS field of each case are used as initial conditions (geostrophically adjusted initial velocity fields are obtained from diagnostic calculation ), while the remaining OTIS fields are used for comparison with the model derived fields. A diagnostic calculation with each OTIS temperature and salinity field provides the corresponding OTIS surface elevation field to be compared with the model surface elevation fields.

During the two periods tested here, there is a distinct difference in the quantity of altimeter data. One of the goals of the study is to evaluate if this has an effect on the skill of the data assimilation. Figure 4 summarizes the amount of altimeter data (data points along satellite tracks crossing the model domain ) available for assimilation during the two periods. About 600 data points per day are available for case 1 , compared to about 400 decreasing to 200 data points per day for case 2 . During the second half of case 2 , there are days with no data. These limited numbers of data points are used to update the $\sim 27000$ model grid points. Examples of the satellite coverage of one 17-day repeat cycle over the model domain during each of the two periods are shown in Fig. 5. During the period in case 1 (e.g., July 1987, Fig. 5a), data along most tracks are complete, except a few descending tracks. However, during the period in case 2 (e.g., July 1988, Fig. 5b), data along most of the descending tracks and along some ascending tracks are missing.

For each of the two cases, two calculations were done: an assimilated model calculation where altimeter data are assimilated once every day into the model, and an unassimilated calculation (which is, actually, a pure forecast, as in Ezer et al. 1992). Both of these runs started from the same initial condition; the surface elevation fields derived from the initial OTIS fields of the two experiments are shown in Fig. 6. Note that, unlike the objective analysis of Ezer et al. (1993) where Geosat data from future and past were used, here we follow a more realistic, operational-like scheme wherein only present data (within a one-day window) are assimilated. The "error" is defined as the difference between the model calculation at a specific time and the corresponding field (e.g., elevation, temperature, etc.) obtained from OTIS at the same time. We note that the OTIS analysis fields used for initialization and comparison do have errors (e.g., they lack small-scale variability far from the Gulf Stream, and do generate some bias via their use of feature models; Ezer et al. 1993). Thus, the actual nowcast error compared to the (unknown) real ocean may be different than that obtained here. In any case, if the data assimilation has any nowcast skill, the nowcast error should be smaller than the forecast error. In the following sections we evaluate the nowcast skill of different oceanic parameters.

\section{b. Surface elevation}

Examples of the surface elevation fields derived from OTIS ( through diagnostic calculations), the assimilated model, and the unassimilated model are shown in Figs. 7 and 8 , for cases 1 and 2, respectively. Since the OTIS fields are dominated by the feature models for the stream and rings, its fields are much smoother, the eddies are usually stronger, and there are no variations far from the stream when compared to the model-derived fields. That eddies are more diffuse and have shorter lifetime in model simulations compared to observations is typical of most types of eddy resolving numerical ocean models (Chassignet 1992) at present day affordable grid resolutions. Assimilation of altimeter data into the model partially corrects this model deficiency.

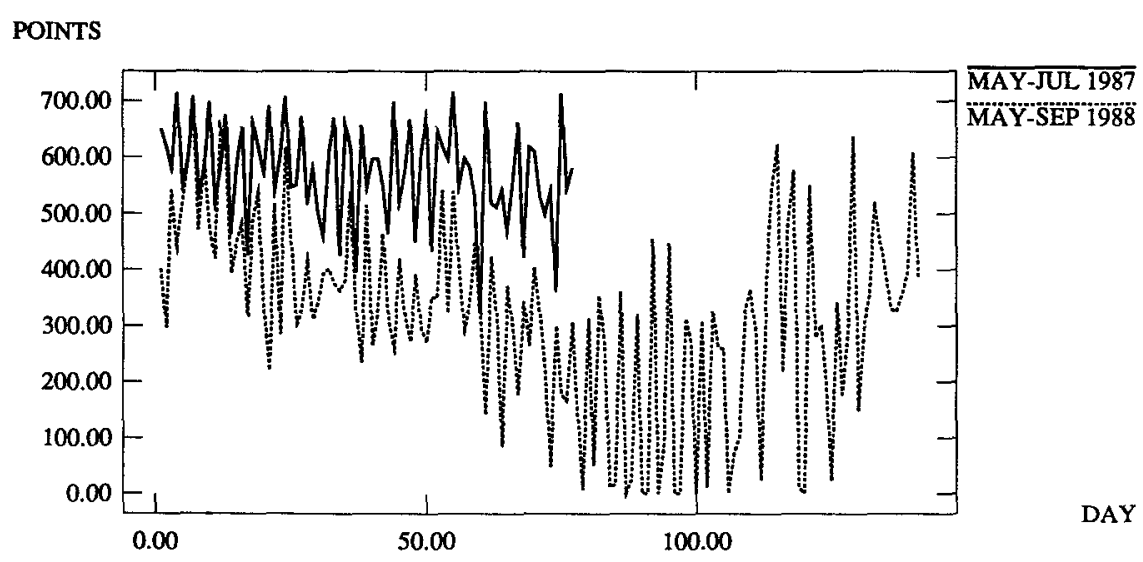

FIG. 4. The number of available altimeter data points per day over the model domain during 6 May-21 July 1987 (solid line) and during 4 May-21 September 1988 (dashed line). 

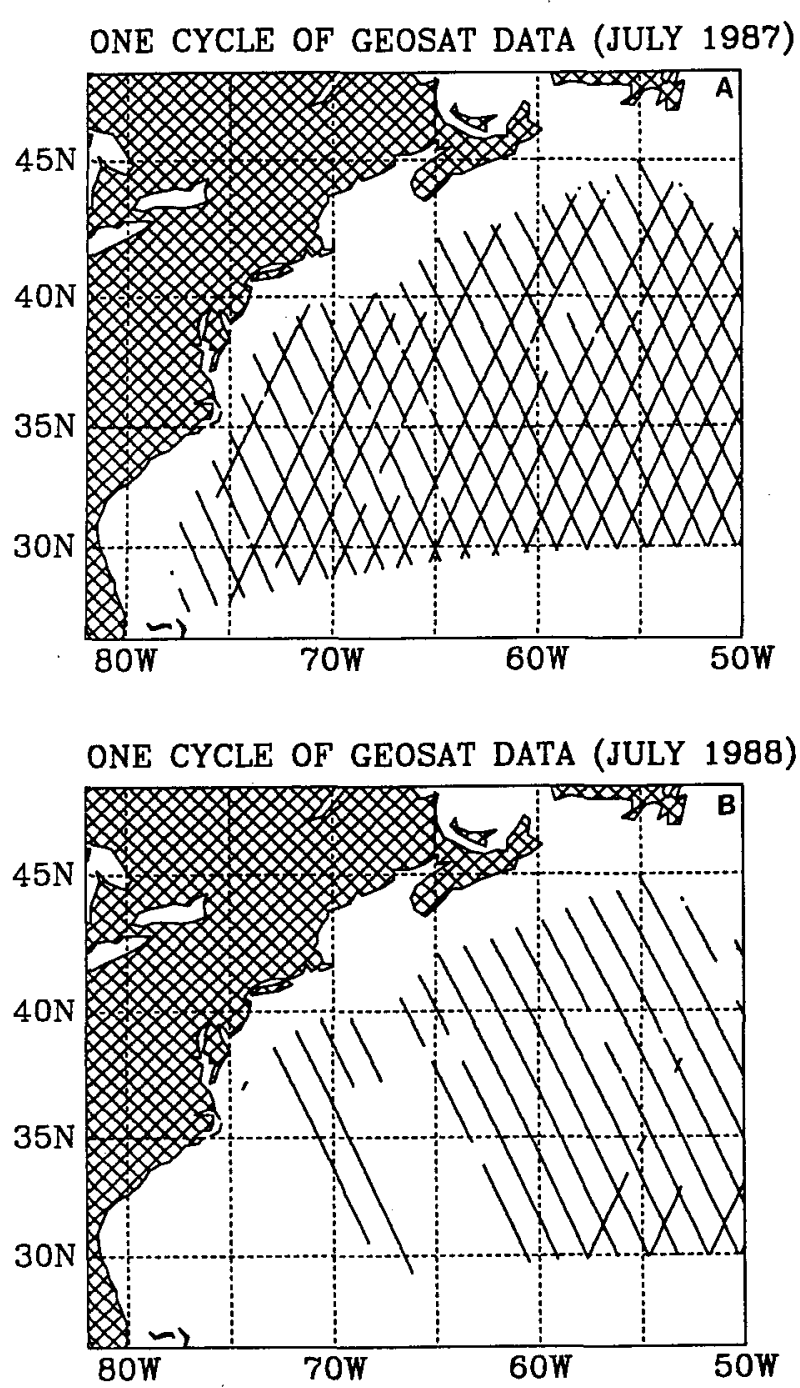

FIG. 5. Examples of the Geosat altimeter data coverage over the model domain during one repeat cycle of 17 days during (a) July 1987 , and (b) July 1988 . Only data for regions with water depth larger than $1000 \mathrm{~m}$ are used.

Previous studies have shown that the model has a forecast skill for 20-40 days when initialized with simulated data (Mellor and Ezer 1991) and at least 14 days when initialized with OTIS data (Ezer et al. 1992). Therefore, we look now in more detail at the synoptic examples in Figs. 7 and 8 to see if assimilation of data can improve the forecast of mesoscale features. For the first 7-14 days, the differences between the assimilated and the unassimilated fields are relatively small; accumulation of altimeter data (one or two tracks per day) is slow and not enough to constrain the model. For example, two weeks after initialization, on 20 May 1987 (Fig. 7a), both the assimilated and the unassimilated model predict the shedding of the cold ring at $37^{\circ} \mathrm{N}, 67^{\circ} \mathrm{W}$ from the meander observed on 6 May 1987 (Fig. 6a), in agreement with OTIS. However, the warm ring that interacts with the stream at $42^{\circ} \mathrm{N}, 57^{\circ} \mathrm{W}$ is better resolved in the assimilated field than in the unassimilated field. Later, on 21 July 1987 (Fig. 7b), the two model calculations depart from each other, and one can see that the general location of the stream is more realistic in the assimilated fields compared to the unassimilated fields. Examples from the second case (initialized with fields from 4 May 1988; Fig. 6b) demonstrate similar patterns (Fig. 8). Mesoscale features that are predicted by the assimilated model include, for example, the large meander at $60^{\circ} \mathrm{W}$ and the warm ring at $57.5^{\circ} \mathrm{W}$ on $13 \mathrm{July} 1988$ (Fig. 8a), as well as the pair of warm rings observed around $42^{\circ} \mathrm{N}, 55^{\circ} \mathrm{W}$ on 27 July 1988 (Fig. 8b). It is obvious from this qualitative comparison that the assimilation is able to constrain the model, so it can produce some of the observed mesoscale variability, although significant differences are still found between the nowcast and the analysis fields.
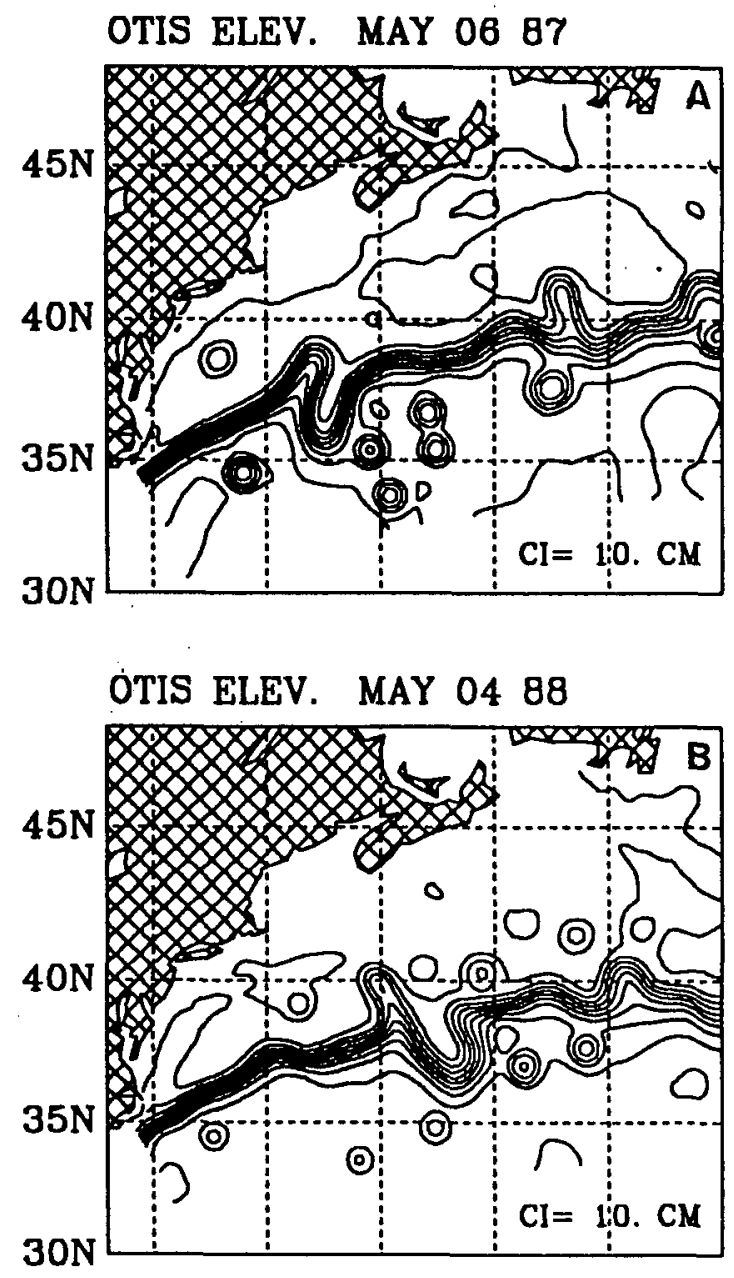

FIG. 6. The surface elevation fields, calculated diagnostically from the OTIS temperature and salinity analysis fields, for the dates used as initial condition in case 1 and 2. (a) 6 May 1987 and (b) 4 May 1988. The contour interval is $10 \mathrm{~cm}$. 
A

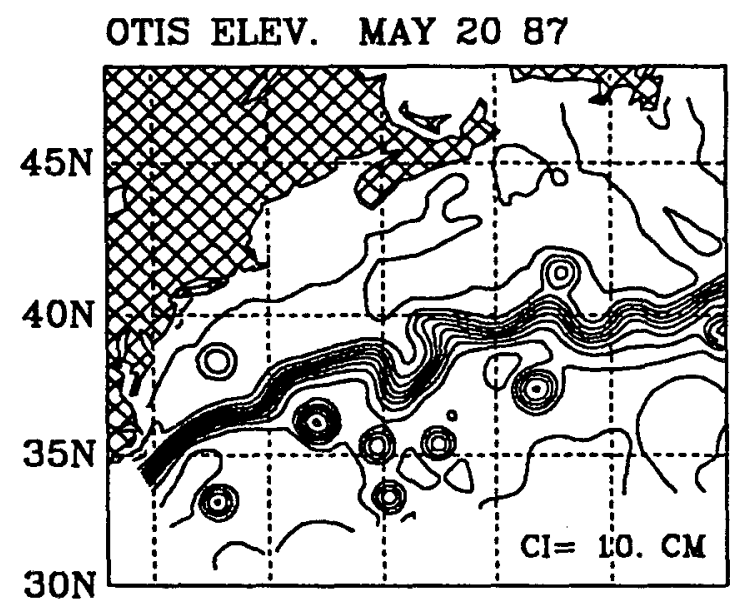

ASS. ELEV. MAY 2087

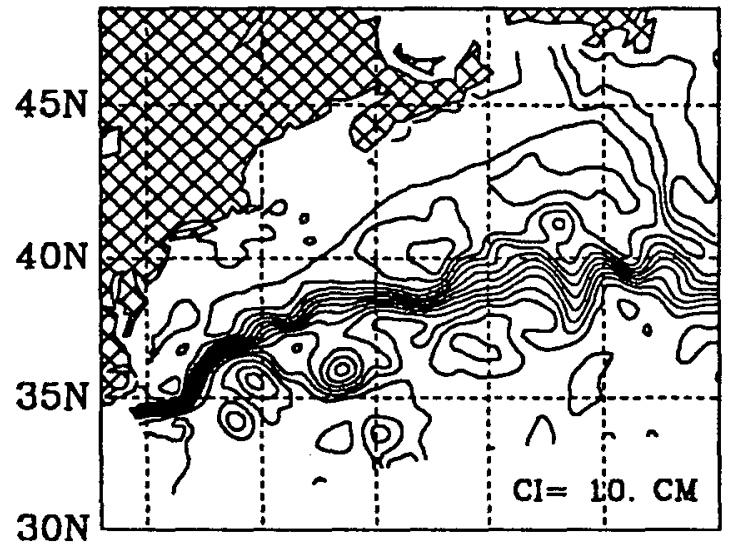

FOR. ELEV. MAY 2087

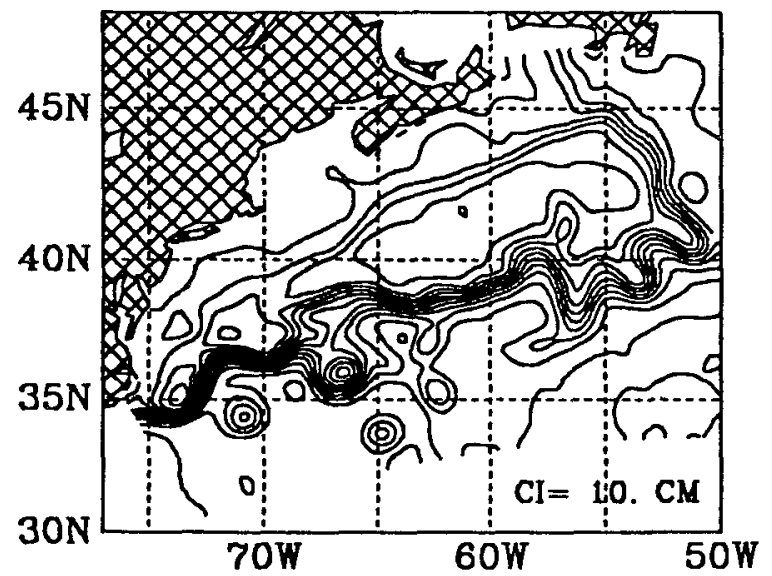

B

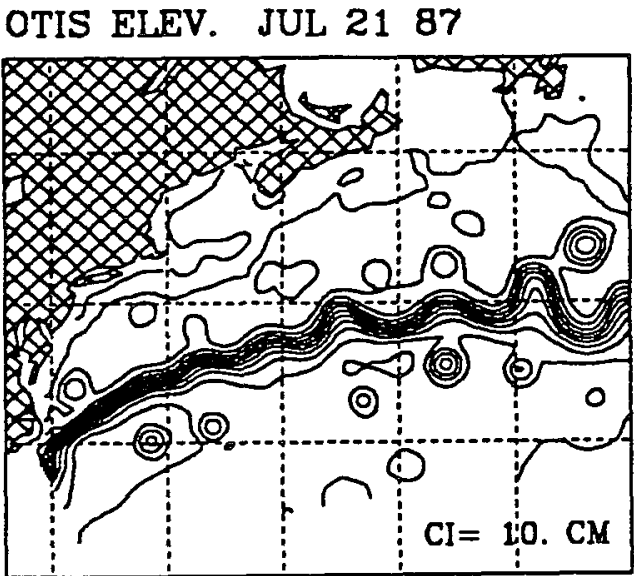

ASS. ELEV. JUL 2187

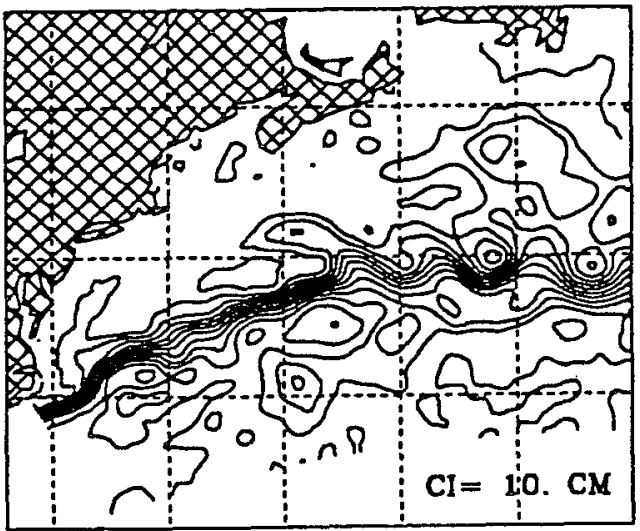

FOR. ELEV. JUL 2187

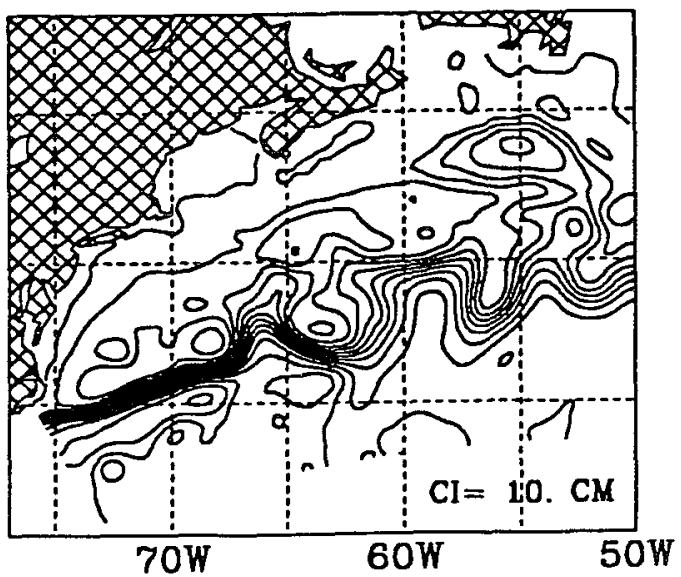

FIG. 7. Examples of synoptic surface elevation fields for case 1 (initialized on 6 May 1987) derived from: diagnostic calculation using OTIS analysis fields (upper panels), assimilated model (middle panels), and the unassimilated model (lower panels). The contour interval is $10 \mathrm{~cm}$. 
A

OTIS ELEV. JUL 1388

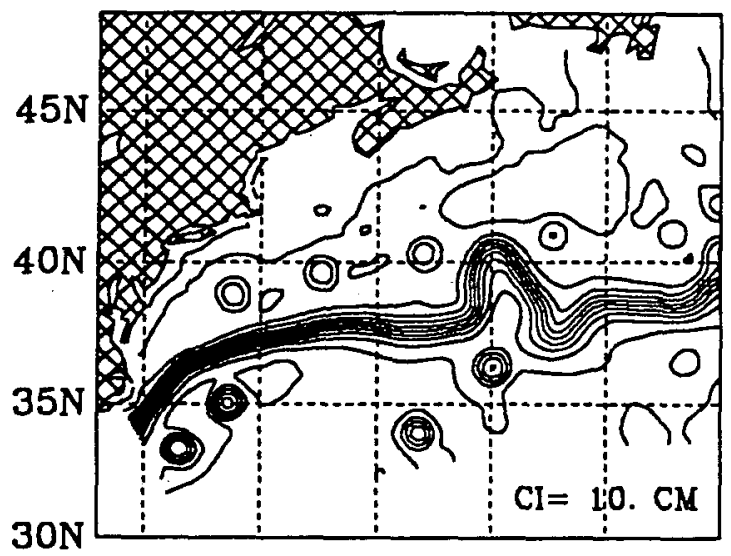

ASS. ELEV. JUL 1388

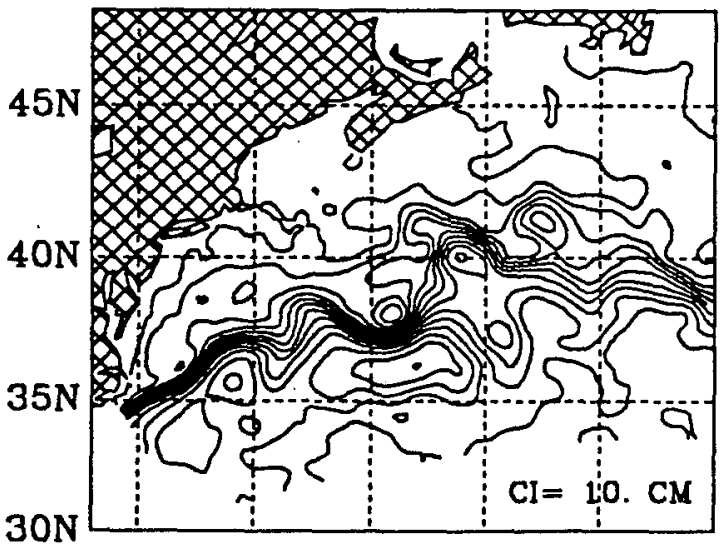

FOR. ELEV. JUL 1388

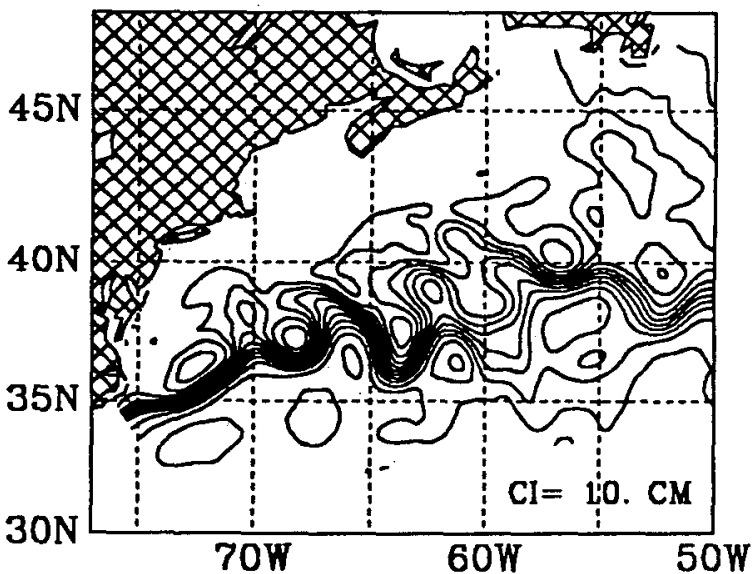

B

OTIS ELEV. JUL 2788

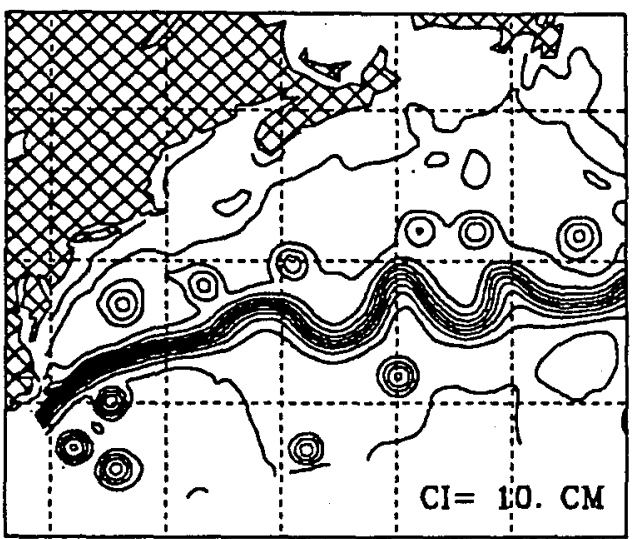

ASS. ELEV. JUL 2788

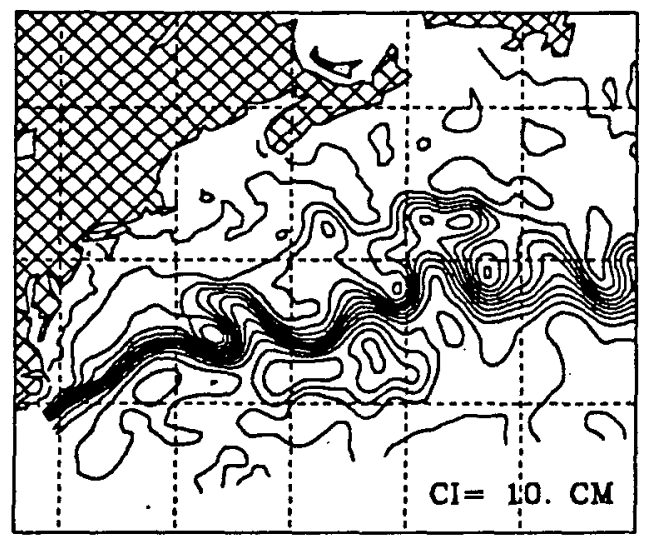

FOR. ELEV. JUL 2788

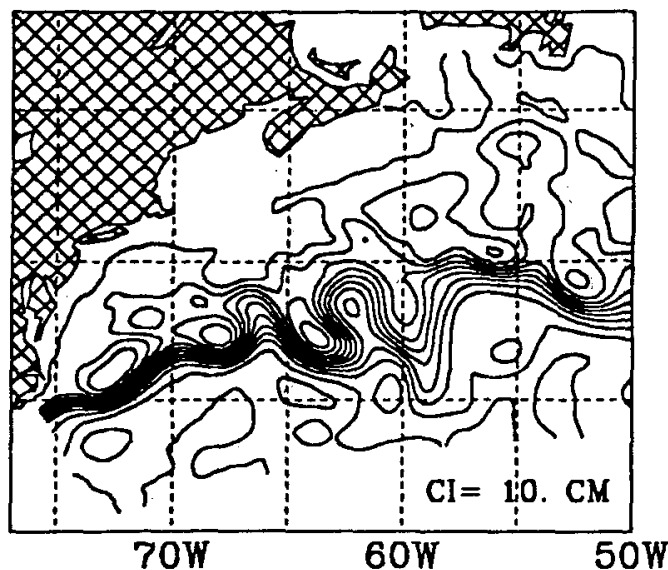

FIG. 8. Same as Fig. 7 but for case 2 initialized on 4 May 1988. 
OTIS GS PATH MAY 6- JUL 211987
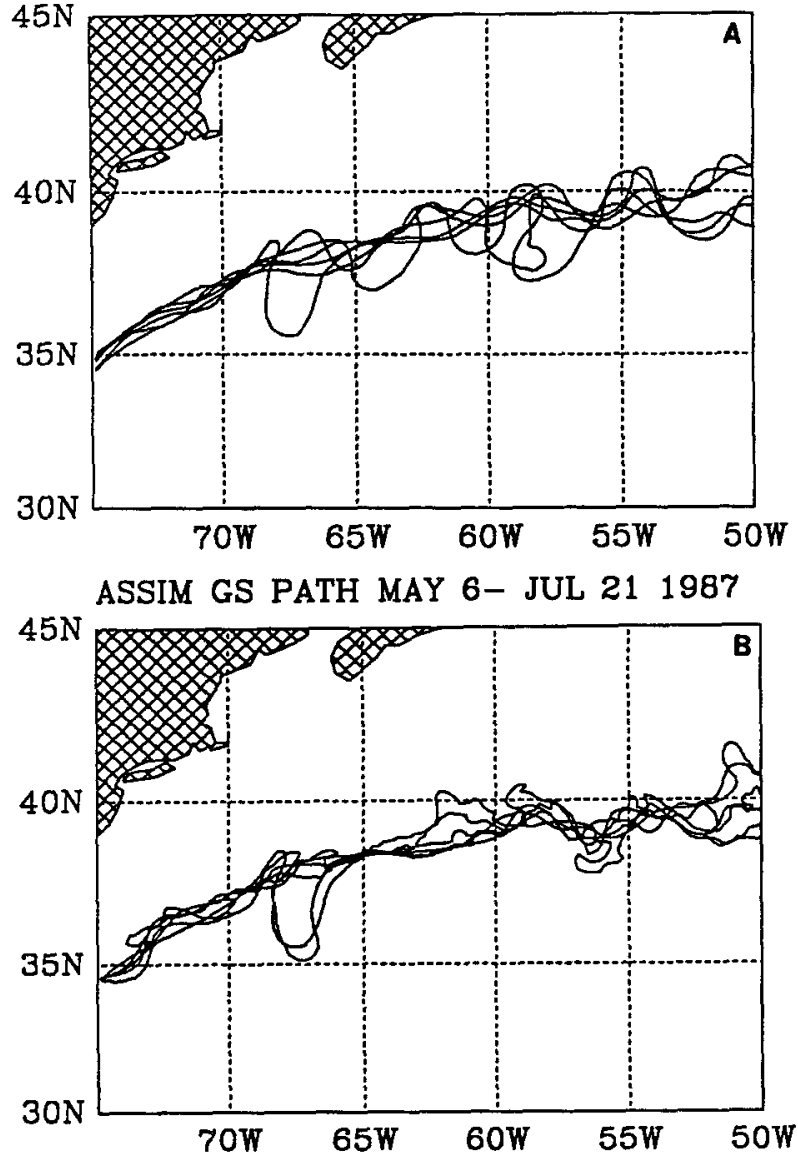

FOREC GS PATH MAY 6- JUL 211987

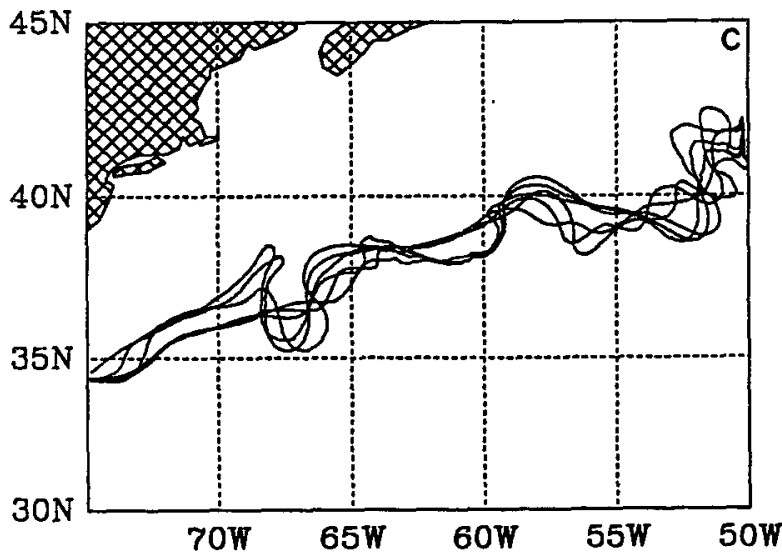

FIG. 9. The Gulf Stream axes (derived from the $12^{\circ} \mathrm{C}$ contour at $500 \mathrm{~m}$ depth) during 6 May-21 July 1987 from (a) OTIS, (b) the assimilated model, and $(\mathrm{c})$ the unassimilated model.

\section{c. Gulf Stream axis position}

To study the variations of the Gulf Stream path, we discuss now the changes in the Gulf Stream axis during the two periods. The evolution of the stream axis, de- fined by the $12^{\circ} \mathrm{C}$ contour at $500 \mathrm{~m}$ depth, are shown in Figs. 9 and 10. Note that near the boundaries, the unassimilated model axis tends to depart from the initial location of the Gulf Stream; the axis shifts southward in the west and northward in the east portion of the domain (Fig. 9c) compared with OTIS fields (Fig.

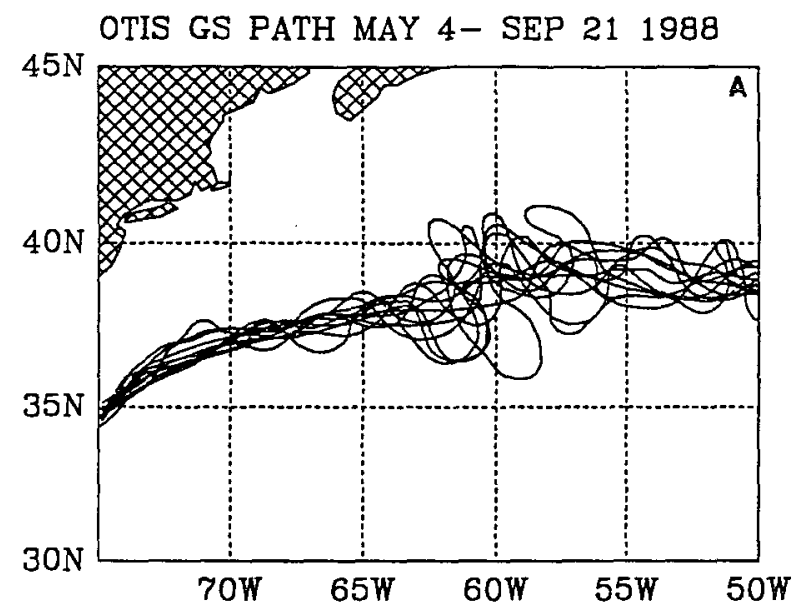

ASSIM GS PATH MAY 4- SEP 211988

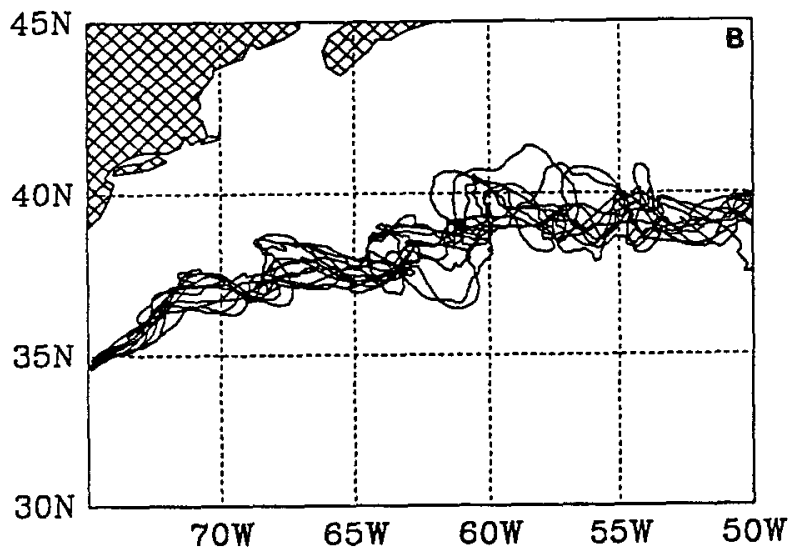

FOREC GS PATH MAY 4- SEP 211988

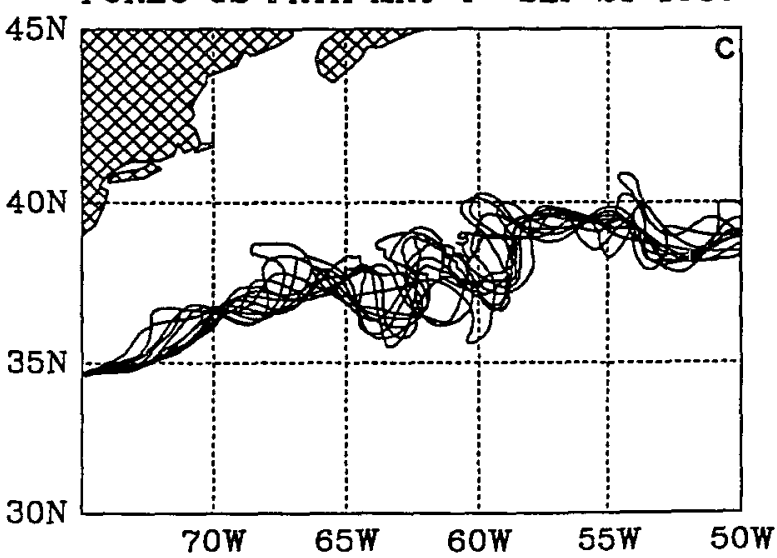

FIG. 10. Same as Fig. 9 but for the period 4 May-21 September 1988. 
9a). The assimilated model (Fig. 9b), however, is able to correct the imperfect boundary effect and to restrain the stream closer to its observed location. As reported in previous studies (Mellor and Ezer 1991; Ezer and Mellor 1992), model variability is reduced near open boundaries. The data assimilation seems to restore some of this variability near the eastern boundary as seen in Fig. 10. Note that, in both the unassimilated and the assimilated model runs, the vertically integrated velocity on open boundaries remains unchanged (and equal to the initial conditions); however, in the future, time-dependent boundary conditions can be forced by the altimeter data and should further improve the nowcast. Visually, it is clear that the axis variations calculated by the assimilated model resemble those of the analysis fields much better than those without assimilation.

After the above descriptive evaluation of the data assimilation scheme, more quantitative assessment is obtained, specifically, a comparison of the unassimilated (forecast) and the assimilated (nowcast) model errors. The assimilated and the unassimilated errors of the Gulf Stream axis are obtained from the area between the OTIS and the modeled axis divided by the length of the path; they are shown for case 1 and case 2 in Figs. $11 \mathrm{a}$ and $11 \mathrm{~b}$, respectively. Also shown in Fig. $11 \mathrm{c}$ is the percent of the assimilated errors compared to the unassimilated errors; for example, $20 \%$ relative error means that the assimilation is able to reduce the error without assimilation by $80 \%$. In both cases the assimilated error is significantly below the unassimilated error for time larger than 7 days after initialization. The maximum reduction of the forecast error due to the assimilation is $\sim 75 \%$ in 1987 (Figs. 11a,c) and $\sim 50 \%$ in 1988 (Figs. $11 \mathrm{~b}, \mathrm{c}$ ). The better skill in case 1 compared with the case 2 is probably due to the better coverage of the altimeter data during this period (Fig. 4).

\section{d. Temperature fields}

Next, we evaluate the vertical distribution of error, in order to directly assess the effectiveness of the projection of surface information into the deep ocean by the correlation technique; we look at the area-averaged rms error (i.e., compared to OTIS fields) of temperature anomalies at different levels, averaged over each period (except for the first 7 days), Fig. 12. Salinity fields are not compared here because of the lesser accuracy of the salinities in the OTIS analysis. The area in which the average is calculated is within $2^{\circ}$ north and south of the mean Gulf Stream location, so regions far from the stream where the quality of the OTIS fields are relatively poor and where variability is relatively small are excluded. The largest forecast and nowcast errors are found around $500 \mathrm{~m}$ depth; however, at this depth, the assimilation is also the most efficient in reducing the errors. The assimilation error is generally smaller
(A) AXIS ERROR (MAY 6 - JUL 21, 1987)

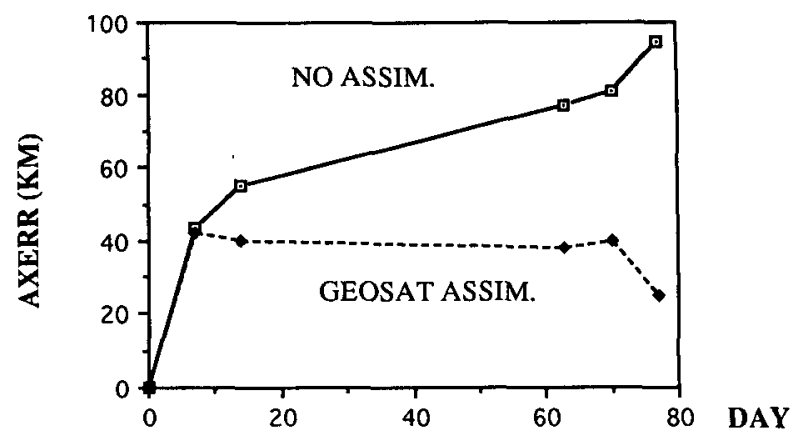

(B) AXIS ERROR (MAY 4 - SEP 21, 1988)

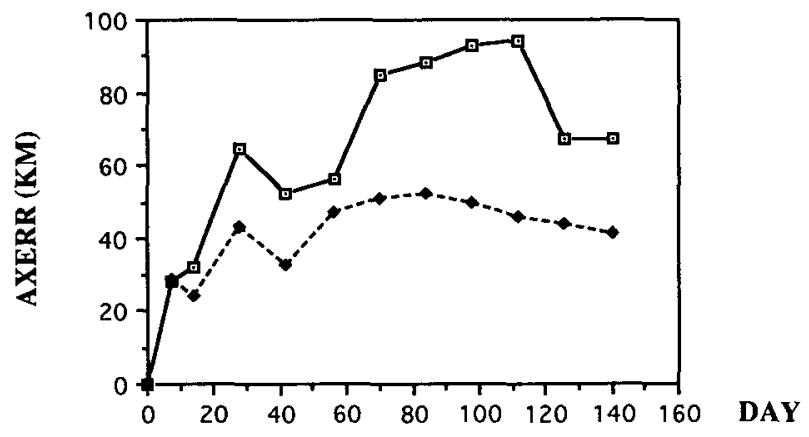

(C) ASSIM / FORECAST AXIS ERROR

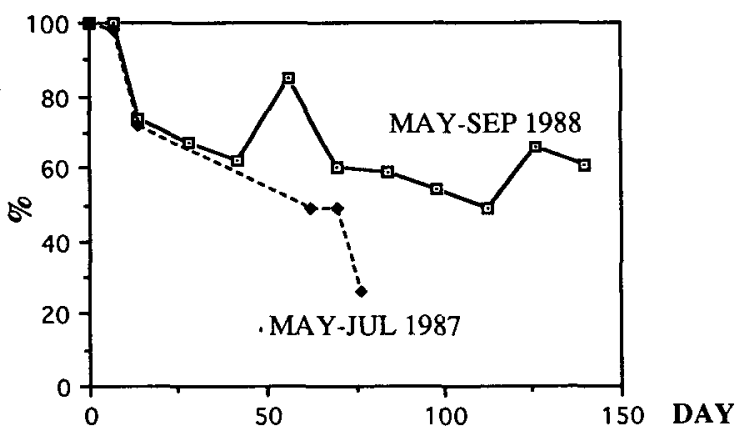

FIG. 11. Gulf Stream axis error of the assimilated model (dashed line) and the forecast model (solid line) as a function of time from initialization. (a) May-July 1987, (b) May-September 1988. (c) The percent of the assimilation error compared to the unassimilated error for the cases in (a) and (b).

than the unassimilated error, with maximum reduction of rms temperature error at $500 \mathrm{~m}$ of about $30 \%$ in 1987 and $15 \%$ in 1988 . The better skill during the first period is, again, due to the better altimetry coverage in 1987. That the assimilation is relatively more effcient at the subsurface depth $(\sim 500 \mathrm{~m})$ is consistent with the vertical distribution of the correlation coefficient ( Fig. 3c); at this depth correlation between surface elevation and subsurface fields is larger. Therefore, larger weight is given to the data [Eq. (17)], and the data constraint on the model is thus stronger. Moreover, the reduction of nowcast skill near the surface and in the deep ocean is also due to the deficiencies in 
TEMP. RMS ERR (MAY-JUL, 1987)

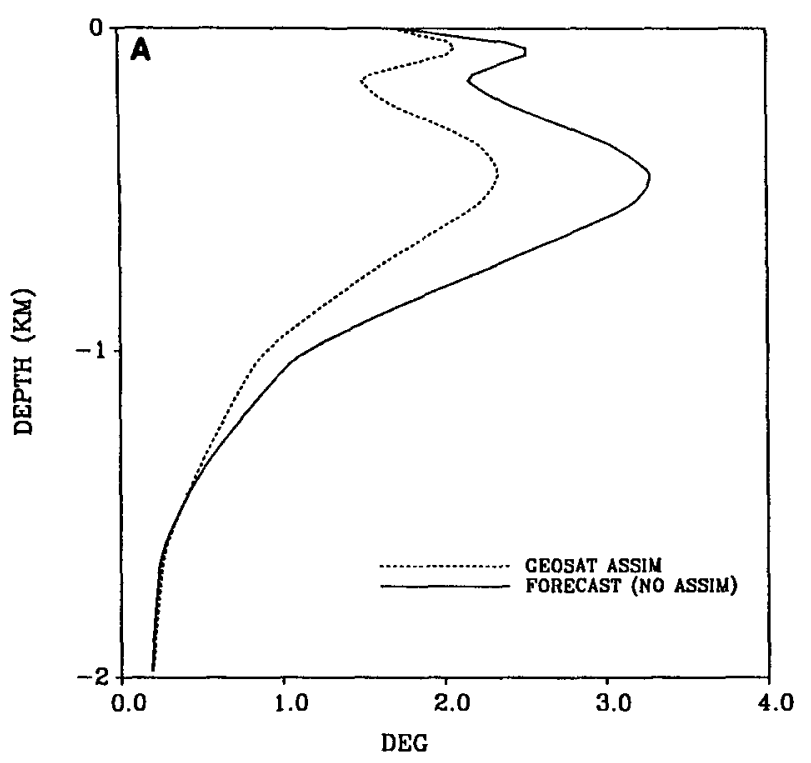

TEMP. RMS ERR (MAY-SEP 1988)

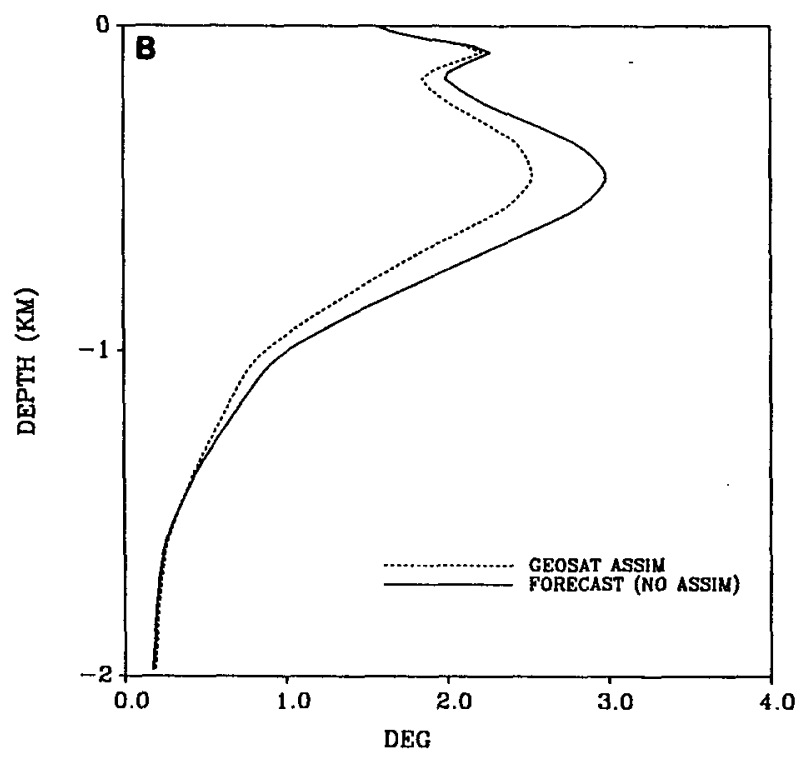

FIG. 12. The vertical distribution of the area-averaged rms error of temperature anomaly for (a) the 1987 case 1 and (b) for the 1988 case 2 . Results from the assimilated model run are indicated by the dashed lines and those from the unassimilated model run by the solid lines. The errors are averaged over all the dates except the first week of the calculations.

the model mixed layer because of the use of monthly climatological surface heat fluxes (instead of synoptic fluxes appropriate for the specific experimental periods) and the use of climatological data in the deep layers of OTIS.

\section{Summary and conclusions}

A data assimilation scheme that uses a three-dimensional optimal interpolation approach and a realistic primitive equation numerical model has been developed and tested, using the Geosat altimeter data for assimilation. Model-derived correlations between surface elevation and subsurface temperature and salinity fields are used to project surface altimeter data into the deep ocean. Errors in these correlations together with model and data error estimates are taken into account when optimizing the assimilation. OTIS analysis fields are used for initialization and for comparison with model fields with and without continuous altimetry assimilation; we refer to differences between model fields and OTIS fields as "errors." This study follows previous studies that used simulated data (e.g., White et al. 1990; Mellor and Ezer 1991) in order to evaluate the effects of errors in the observed data.

The first observation that should be made is thatalthough significant progress toward a realistic model of the Gulf Stream has been made in the last few years-the model's grid resolution is still inadequate. Eddies decay too fast and they are, on average, too large.

The large domain produces Gulf Stream separation that seems more realistic than the otherwise satisfying results of Mellor and Ezer (1991) and Ezer and Mellor (1992), who used a somewhat smaller and lower-resolution model. However, when we reduced the size of the former model as shown in Fig. 1, it produced a Gulf Stream jet directed south of that produced by the larger model and south of all the OTIS fields (see upper and lower panels in Figs. 7 and 8 ) and an overall stream location with a southward bias. This resulted from the use of (constant) lateral boundary conditions derived diagnostically from the larger model and the OTIS initial fields of 6 May 1987 and 4 May 1988. However, for present purposes, the bias is somewhat fortuitous in that, shortly downstream from Hatteras, we see a demonstration that the data assimilation repaired some of the damage (see middle panels in Figs. 7 and 8 ).

The "identical twin" experiments of Mellor and Ezer (1991) used subsampled model elevation data to provide surrogate altimeter data. A major advantage of this approach is that one has complete "true" ocean data (in contrast to OTIS fields, which are based on very incomplete data) with which to compare assimilated model output. Furthermore, in the identical twin exercise, the model was perfect (by definition, model processes exactly correspond to "true" ocean processes), the data were perfect, although sparse, and the mean "altimetry" fields were identical to the model's mean elevation fields. We found that, when data were available at all model grid points, the reduction of the 500-m temperature rms error compared to a case without assimilation was about $80 \%$. When data coverage was reduced to that along Geosat tracks, the reduction 
of error was $40 \%-50 \%$. For comparison, in this paper where real data are used, the model is not perfect, nor is the data, and the mean altimetry field does not coincide with the model's mean elevation field. Therefore, the reduction in the $500-\mathrm{m}$ temperature $\mathrm{rms}$ error of the assimilated model fields relative to the unassimilated fields was only $15 \%-30 \%$; the latter includes unknown OTIS errors. While the skill in nowcasting temperature variations using altimetry as the only source of data was relatively small, much better skill has been demonstrated in nowcasting Gulf Stream axis location; the reduction in Gulf Stream location error was about $40 \%$, for the 1988 case when data coverage was relatively poor, and $75 \%$ for the 1987 case.

There are several possible sources to the assimilated axis errors of $20-50 \mathrm{~km}$ (Figs. 11 a,b): model errors, assimilation scheme errors, Geosat altimetry errors, and OTIS errors. We should keep in mind, again, that the OTIS fields do have significant errors compared with the real ocean or with other data. Ezer et al. (1993) compared the Gulf Stream axis derived from OTIS to that derived from the Geosat altimeter, and found an rms difference of about $25 \mathrm{~km}$ between the two. This difference is due to errors in locating the Gulf Stream north wall from SST data, and the errors in the OTIS feature model used to project the north wall location into the deep layers. Model errors consist, for example, of small-scale variations that are missing from the data but produced by the model, together with phase errors in propagating meanders and eddies. Assimilation scheme errors consist of errors in the correlation factors and in the optimal interpolation (e.g., dependency on chosen parameters such as time and length scales, Ezer et al. 1993). There are also orbit and atmospheric correction errors in the Geosat data.

Although the results of this study are encouraging, error sources are numerous, but their magnitudes should decrease in the future. Model resolution will continue to improve and model-generated errors should decrease; that is, $T_{C}$ in Eq. (12) should increase. The lateral boundary condition should be-improved; for example, we may simply return to the larger model domain, or use the altimetry data near the open boundary as a boundary condition for surface elevation. Rather than assume that the model mean elevation fields are coincident with the altimeter mean fields, there might be benefit in introducing geoid information (Kelly 1991; Glenn et al. 1991; Ezer et al. 1993) into the system. Better quality and coverage of the satellite altimeter data and better estimates of the geoid are expected in the future with the launching of several new satellites. We shall assimilate other data such as SST data directly into the dynamic model as is done in OTIS analysis; this possibility has been partially broached by Ezer et al. (1991). The addition of SST data could especially improve the nowcast skill in the near-surface layers and in shallow water where altimetry assimilation is less effective. The use of XBT data is another possibility [e.g., as in the global data assimilation system of Derber and Rosati (1989)]. Recent observations of mesoscale variability in the Gulf Stream (e.g., from the Synoptic Ocean Prediction, SYNOP, field program), will provide additional data for assimilation and comparison with model results and will increase our understanding of dynamical processes of the Gulf Stream system.

Acknowledgments. This study is part of the Data Assimilation and Model Evaluation Experiments (DAMEE) organized by the Institute for Naval Oceanography (INO). The support of the INO under Contract INO-S8751, the support of the Office for Naval Research (the Navy Ocean Modeling and Prediction Program) under Contract N0014-93-1-10037, and the additional support from the National Ocean Service, and the NOAA's Geophysical Fluid Dynamics Laboratory are gratefully acknowledged.

\section{REFERENCES}

Blumberg, A. F., and G. L. Mellor, 1987: A description of a threedimensional coastal ocean circulation model. Three-Dimensional Coastal Ocean Models, Vol. 4, N. Heaps, Ed., Amer. Geophys. Union, $208 \mathrm{pp}$.

Carnes, M. R., J. L. Mitchell, and P. W. deWitt, 1990: Synthetic temperature profiles derived from Geosat altimetry: Comparison with air-dropped expendable bathythermograph profiles. $J$. Geophys. Res., 95, 17 979-17 992.

Chassignet, E. P., 1992: Rings in numerical models of ocean general circulation: A statistical study. J. Geophys. Res., 97, 9479-9492.

Clancy, R. M., P. A. Phoebus, and K. D. Pollak, 1990: An operational global-scale ocean thermal analysis system. J. Atmos. Oceanic Technol., 7, 233-254.

, J. M. Harding, K. D. Pollak, and P. May, 1992: Quantification of improvements in an operational global-scale ocean thermal analysis system. J. Atmos. Oceanic Technol., 9, 55-65.

Cummings, J. A., and M. J. Ignaszewski, 1991: The Fleet Numerical Oceanography Center regional ocean analysis system. MTS ' 91 , Proc. Mar. Technol. Soc., New Orleans, The Mar. Technol. Soc., 1123-1129.

Derber, J., and A. Rosati, 1989: A global oceanic data assimilation system. J. Phys. Oceanogr., 19, 1333-1347.

Dombrowsky, E., and P. De May, 1992: Continuous assimilation in an open domain of the northeast Atlantic 1. Methodology and application to AthenA-88. J. Geophys. Res., 97, 9719-9731.

Ezer, T:, 1994: On the interaction between the Gulf Stream and the New England Seamounts Chain. J. Phys. Oceanogr., 24, 191204.

-, and G. L. Mellor, 1992: A numerical study of the variability and the separation of the Gulf Stream, induced by surface atmospheric forcing and lateral boundary flows. J. Phys. Oceanogr., 22, 660-682.

_ - and D.-S. Ko, 1991: Nowcasting the Gulf Stream structure with a primitive equation model and assimilation of altimetry and SST data. MTS '91, Proc. Mar. Technol. Soc., New Orleans, The Mar. Technol. Soc., 236-241.

- D. S. Ko, and G. L. Mellor, 1992: Modeling and forecasting the Gulf Stream. Oceanic and atmospheric nowcasting and forecasting, Mar. Tech. Soc. J., 26(2), 5-14.

- G. L. Mellor, D.-S. Ko, and Z. Sirkes, 1993: A comparison of Gulf Stream sea surface height fields derived from Geosat altimeter data and those derived from sea surface temperature data. J. Atmos. Oceanic Technol., 10, 76-87.

Galperin, B., and G. L. Mellor, 1990a: A time-dependent, threedimensional model of the Delaware Bay and River. Part 1: De- 
scription of the model and tidal analysis. Estuar., Coastal Shelf Sci., 31, 231-253.

- , and - 1990b: A time-dependent, three-dimensional model of the Delaware Bay and River. Part 2: Three-dimensional flow fields and residual circulation. Estuar., Coastal Shelf Sci., 31, 255-281.

Ghil, M., and P. Malanotte-Rizzoli, 1991: Data assimilation in meteorology and oceanography. Vol. 33, Advances in Geophysics, Academic Press, 141-265.

Glenn, S. M., D. L. Porter, and A. R. Robinson, 1991: A synthetic geoid validation of Geosat mesoscale dynamic topography in the Gulf Stream region. J. Geophys. Res., 96, 7145-7166.

Gustafsson, N., 1981: A review of methods for objective analysis. Dynamic Meteorology: Data Assimilation Methods, Vol. 36, L. Bengtsson, M. Ghil, and E. Kallen, Eds., Springer-Verlag, 1776.

Haines, K., 1991: A direct method for assimilating sea surface height data into ocean models with adjustment to the deep circulation. J. Phys. Oceanogr., 21, 843-868.

Holland, W. R., and P. Malanotte-Rizzoli, 1989: Assimilation of altimeter data into an ocean model: Space verses time resolution studies. J. Phys. Oceanogr., 19, 1507-1534.

Kelly, K. A., 1991: The meandering Gulf Stream as seen by the Geosat altimeter: surface transport, position, and velocity variance from $73^{\circ}$ to $46^{\circ} \mathrm{W}$. J. Geophys. Res., 96, 16 721-16 738 .

Leese, J. A., R. C. Willems, and L. A. Yeske, 1992: Evaluation capability for the Navy ocean modeling and prediction program. Oceanography, 5, 610-619.

Leith, C. E., 1987: Objective methods for weather prediction. Annu. Rev. Fluid Mech., 10, 107-128.

Mellor, G. L., 1992: User's guide for a three-dimensional, primitive equation, numerical ocean model. Program in Atmospheric and Oceanic Sciences, Princeton University, 35 pp.

model for geophysical fluid problems. Rev. Geophys., 20, 851875.

- , and T. Ezer, 1991: A Gulf Stream model and an altimetry assimilation scheme. J. Geophys. Res., 96, 8779-8795.
- C. Mechoso, and E. Keto, 1982: A diagnostic calculation of the general circulation of the Atlantic Ocean. Deep-Sea Res., 29, 1171-1192.

Miller, R. N., 1989: Direct assimilation of altimetric differences using the Kalman filter. Dyn. Atmos. Oceans, 13, 317-334.

Moore, A. M., 1991: Data assimilation in a quasi-geostrophic openocean model of the Gulf Stream region using the adjoint method. J. Phys. Oceanogr., 21, 398-427.

Oberhuber, J. M., 1988: An atlas based on the COADS data set: The budgets of heat, buoyancy and turbulent kinetic energy at the surface of the global ocean. Max-Planck Institut fur Meteorologie, Rep. No. 15

Oey, L.-Y., G. L. Mellor, and R. I. Hires, 1985a: A three-dimensional simulation of the Hudson-Raritan estuary. Part I: Description of the model and model simulations. J. Phys. Oceanogr., 15, 1676-1692.

$\longrightarrow, \ldots$, and $-1985 \mathrm{~b}$ : A three-dimensional simulation of the Hudson-Raritan estuary. Part II: Comparison with observation. J. Phys. Oceanogr., 15, 1693-1709.

- , T. Ezer, G. L. Mellor, and P. Chen, 1992: A model study of "bump" induced western boundary current variabilities. J. Mar. Sys., 3, 321-342.

Parrish, D. F., and J. C. Derber, 1992: The National Meteorological Center's spectral statistical-interpolation analysis system. Mon. Wea. Rev., 120, 1747-1763.

Robinson, A. R., M. A. Spall, L. J. Walsted, and W. G. Leslie, 1989: Data assimilation and dynamic interpolation in Gulfcast experiments. Dyn. Atmos. Oceans, 13, 301-316.

Sirkes, Z., and C. Wunsch, 1990: Note on apparent systematic and periodic errors in Geosat orbits. Geophys. Res. Lett., 17, 13071310.

Verron, J., 1992: Nudging satellite altimeter data into quasi-geostrophic ocean model. J. Geophys. Res., 97, 7479-7491.

White, W. B., C.-K. Tai, and W. R. Holland, 1990: Continuous assimilation of simulated Geosat altimetric sea level into an eddyresolving numerical ocean model. 1 . Sea level differences. $J$. Geophys. Res., 95, 3219-3234.

Zou, X., I. M. Navon, and F. X. LeDimet, 1992: An optimal nudging data assimilation scheme using parameter estimation. Quart. $J$. Roy. Meteor. Soc., 118, 1163-1186. 